\title{
Observations of the boundary layer, cloud, and aerosol variability in the southeast Pacific near-coastal marine stratocumulus during VOCALS-REx
}

\author{
X. Zheng ${ }^{1}$, B. Albrecht ${ }^{1}$, H. H. Jonsson ${ }^{2}$, D. Khelif ${ }^{3}$, G. Feingold ${ }^{4}$, P. Minnis ${ }^{5}$, K. Ayers ${ }^{5}$, P. Chuang ${ }^{6}$, S. Donaher ${ }^{1}$, \\ D. Rossiter ${ }^{6}$, V. Ghate ${ }^{7}$, J. Ruiz-Plancarte ${ }^{3}$, and S. Sun-Mack ${ }^{8}$ \\ ${ }^{1}$ Division of Meteorology and Physical Oceanography, Rosenstiel School of Marine and Atmospheric Science, University of \\ Miami, Miami, FL, USA \\ ${ }^{2}$ Naval Postgraduate School, Monterey, CA, USA \\ ${ }^{3}$ University of California, Irvine, Irvine, CA, USA \\ ${ }^{4}$ NOAA Earth System Research Laboratory (ESRL), Boulder, CO, USA \\ ${ }^{5}$ NASA Langley Research Center, Hampton, USA \\ ${ }^{6}$ University of California, Santa Cruz, Santa Cruz, CA, USA \\ ${ }^{7}$ Rutgers University, New Brunswick, NJ, USA \\ ${ }^{8}$ Science Systems and Applications, Inc., Hampton, VA, USA
}

Received: 7 May 2011 - Published in Atmos. Chem. Phys. Discuss.: 20 May 2011

Revised: 5 September 2011 - Accepted: 17 September 2011 - Published: 27 September 2011

\begin{abstract}
Aircraft observations made off the coast of northern Chile in the Southeastern Pacific $\left(20^{\circ} \mathrm{S}, 72^{\circ} \mathrm{W}\right.$; named Point Alpha) from 16 October to 13 November 2008 during the VAMOS Ocean-Cloud- Atmosphere-Land StudyRegional Experiment (VOCALS-REx), combined with meteorological reanalysis, satellite measurements, and radiosonde data, are used to investigate the boundary layer (BL) and aerosol-cloud-drizzle variations in this region. On days without predominately synoptic and meso-scale influences, the BL at Point Alpha was typical of a non-drizzling stratocumulus-topped BL. Entrainment rates calculated from the near cloud-top fluxes and turbulence in the BL at Point Alpha appeared to be weaker than those in the BL over the open ocean west of Point Alpha and the BL near the coast of the northeast Pacific. The cloud liquid water path (LWP) varied between $15 \mathrm{~g} \mathrm{~m}^{-2}$ and $160 \mathrm{~g} \mathrm{~m}^{-2}$. The BL had a depth of $1140 \pm 120 \mathrm{~m}$, was generally well-mixed and capped by a sharp inversion without predominately synoptic and mesoscale influences. The wind direction generally switched from southerly within the BL to northerly above the inversion. On days when a synoptic system and related mesoscale costal circulations affected conditions at Point Alpha (29 October-
\end{abstract}

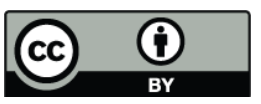

Correspondence to: X. Zheng (xzheng@rsmas.miami.edu)
4 November), a moist layer above the inversion moved over Point Alpha, and the total-water mixing ratio above the inversion was larger than that within the BL.

The accumulation mode aerosol varied from 250 to $700 \mathrm{~cm}^{-3}$ within the BL, and $\mathrm{CCN}$ at $0.2 \%$ supersaturation within the BL ranged between 150 and $550 \mathrm{~cm}^{-3}$. The main aerosol source at Point Alpha was horizontal advection within the BL from south. The average cloud droplet number concentration ranged between 80 and $400 \mathrm{~cm}^{-3}$. While the mean LWP retrieved from GOES was in good agreement with the in situ measurements, the GOES-derived cloud droplet effective radius tended to be larger than that from the aircraft in situ observations near cloud top. The aerosol and cloud LWP relationship reveals that during the typical wellmixed BL days the cloud LWP increased with the CCN concentrations. On the other hand, meteorological factors and the decoupling processes have large influences on the cloud LWP variation as well.

\section{Introduction}

The marine stratocumulus $(\mathrm{Sc})$ deck overlaying the Southeast (SE) Pacific Ocean is the most persistent in the world (Bretherton et al., 2004) with a monthly stratus cloud amount exceeding $40 \%$ throughout the year (Klein and Hartmann,

Published by Copernicus Publications on behalf of the European Geosciences Union. 
1993). There have been few observational studies in the SE Pacific until the last decade or so, when several research cruises were conducted to study marine Sc and marine boundary layer (BL) processes in the SE Pacific. The CIMAR-5 (Garreaud et al., 2001), East Pacific Investigation of Climate (EPIC) 2001 (Bretherton et al., 2004), PanAmerican Climate Studies (PACS) Stratus 2003 (Kollias et al., 2004), and Stratus 2004 (Serpetzoglou et al., 2008) research cruises explored the BL over the subtropical SE Pacific more than $1000 \mathrm{~km}$ offshore. CIMAR-5 provided a transect of the SE Pacific boundary layer at $27^{\circ} \mathrm{S}$ between the Chilean coast $\left(71^{\circ} \mathrm{W}\right)$ and Easter Island $\left(110^{\circ} \mathrm{W}\right)$ during late October 1999. It revealed the east-west increase in the BL depth from less than $1000 \mathrm{~m}$ near the coast to over $2000 \mathrm{~m}$ at the far end of the transect. The other research cruises included 5-6 days of observations at the Stratus Ocean Reference Station (Stratus ORS, $20^{\circ} \mathrm{S}, 85^{\circ} \mathrm{W}$ ) (Cronin et al., 2002; Bretherton et al., 2004; Ghate et al., 2009). The EPIC 2001 observations were made in October - the month with the maximum climatological stratus cloud amount (Klein and Hartmann, 1993; Ghate et al., 2009). During this cruise the $\mathrm{BL}$ at the Stratus ORS was usually well-mixed and covered by a solid Sc layer with a thickness of less than $500 \mathrm{~m}$. The clouds were close to adiabatic (Bretherton et al., 2004). The most variable cloud conditions were observed in November during PACS Stratus 2003 (Kollias et al., 2004) when solid $\mathrm{Sc}$, broken cloud, clear sky, and drizzle were observed. The BL depth was about $1200 \mathrm{~m}$ and the mean cloud base was around $1000 \mathrm{~m}$. In December during the PACS Stratus 2004 study, the BL depth reached about $1400 \mathrm{~m}$ and the decoupled BL structure dominated (Serpetzoglou et al., 2008). These observations revealed the complex structures and the variability in the BL and the cloud layers. Most of the previous field experiments in the SE Pacific focused on the open ocean area, but the near-coastal marine Sc in the SE Pacific has been largely unexplored.

The annual mean of the satellite-derived cloud droplet number concentration $\left(N_{\mathrm{d}}\right)$ over the SE Pacific ocean during 2000-2008 shows a narrow band of high $N_{\mathrm{d}}$ along the coast between $17^{\circ} \mathrm{S}$ and $30^{\circ} \mathrm{S}$, in contrast to the broad Sc area with low $N_{\mathrm{d}}$ over the open ocean (George and Wood, 2010). The strong gradient of $N_{\mathrm{d}}$ over this region, due to influences of both clean marine air masses and anthropogenic aerosol releases along the Chilean and Peruvian coasts, shows both temporal and spatial variations and provides a unique area to study aerosol-cloud interactions. Wood and Bretherton (2004) estimated BL depth, entrainment rate and decoupling over this region using NCEP reanalysis data and satellite observations. They found that the BL depths over this region are generally 100-200 m deeper than those off the coast of California, and the BLs tend to be less decoupled than those over the coastal regions of the Northeast (NE) Pacific. However, it is difficult to establish the generality of previous studies based on remote sensing observations and reanalysis products due to the absence of in situ observations. Further, previous studies have shown that the coastal $\mathrm{BL}$ around $20^{\circ} \mathrm{S}$ has several features different from the coastal BL north or south of this region (Zuidema et al., 2009; Rahn and Garreaud, 2010a). Satellite retrievals show that the monthly mean cloud-top height in the coastal region around $20^{\circ} \mathrm{S}$ could be about $300 \mathrm{~m}$ higher than the surrounding region (Zuidema et al., 2009). Simulation of the observed elevated inversion height in this coastal region is a major challenge for the regional atmospheric numerical modeling community (e.g., Rahn and Garreaud, 2010a, b; Wyant et al., 2010). It has been speculated that since current models can not sufficiently represent the blocking effect of the steep Andes on the flows, simulations tend to produce unrealistically large divergence in the coastal region, which suppresses the BL depth and thins the cloud layer (Rahn and Garreaud, 2010a; Jiang et al., 2010; Wang et al., 2011). In situ observations could help the modeling community improve simulations in the coastal region by offering a variety of measurements within and above the BL.

The VAMOS (Variability of the American Monsoons) Ocean-Cloud-Atmosphere-Land Study-Regional Experiment (VOCALS-REx), which took place in the area extending from the near-coastal region of northern Chile and southern Peru to the remote ocean in the SE Pacific from October to November 2008, aimed at (1) further understanding aerosol-cloud-drizzle interactions in the BL; and (2) improving model simulations and predictions of the SE Pacific coupled ocean-atmosphere-land system on a variety of scales (Wood et al., 2011). For the atmospheric observational component, VOCALS gathered an intensive dataset along $20^{\circ} \mathrm{S}$ from $70^{\circ} \mathrm{W}$ to $85^{\circ} \mathrm{W}$ to study the BL structure, lower free troposphere, cloud properties, and precipitation. The multi-platform observations during VOCALS revealed that the Sc-topped BL depth deepens from $\sim 1000 \mathrm{~m}$ near shore to $\sim 1600 \mathrm{~m}$ at a distance of about $1500 \mathrm{~km}$ offshore (Bretherton et al., 2010). The observed BL in the coastal region is well-mixed with little or no drizzle in the Sc layer. As one component of the five aircraft and two research vessels in the VOCALS experiment, the Center for Interdisciplinary Remotely-Piloted Aircraft Studies (CIRPAS) Twin Otter aircraft focused on making observations off the coast of Northern Chile. Comprehensive in situ observations of aerosol, turbulence, cloud properties, and drizzle were also collected. These offered a unique opportunity to acquire first-hand evidence of cloud-aerosol-turbulence interactions in the nearcoastal marine Sc over the SE Pacific ocean.

In this study, we combine the in situ aircraft data collected by CIRPAS Twin Otter with meteorological reanalysis, satellite-derived cloud properties, and radiosonde data to explore the BL structure and physical properties of clouds and aerosol over the coastal region in the SE Pacific. The goal is to characterize variations of the near-coastal BL, clouds, and aerosols in the SE Pacific. Section 2 describes the aircraft data and the other data supplements. The general synoptic conditions during VOCALS-REx are reviewed 
Table 1. Flight list.

\begin{tabular}{|c|c|c|c|c|c|c|c|c|c|}
\hline Flight & RF01 & RF02 & RF03 & RF04 & RF05 & RF06 & RF07 & RF08 & RF09 \\
\hline Date & 16 Oct & 18 Oct & 19 Oct & 21 Oct & 22 Oct & 24 Oct & 26 Oct & 27 Oct & 29 Oct \\
\hline Time (UTC*) & $14: 10-18: 40$ & $11: 10-15: 40$ & $10: 50-15: 40$ & 11:00-15:30 & $11: 00-15: 40$ & $11: 00-15: 50$ & 11:00-16:00 & $14: 50-19: 40$ & $11: 00-15: 50$ \\
\hline Descriptor & Typical & Typical & Typical & Typical & Typical & $\begin{array}{l}\text { Decoupled, } \\
\text { wind shear in } \\
\text { BL, cirrus }\end{array}$ & Typical & Typical & Decoupled \\
\hline Flight & RF10 & RF11 & RF12 & RF13 & RF14 & RF15 & RF16 & RF17 & RF18 \\
\hline Date & 30 Oct & $1 \mathrm{Nov}$ & 2 Nov & 4 Nov & 8 Nov & 9 Nov & 10 Nov & 12 Nov & $13 \mathrm{Nov}$ \\
\hline Time (UTC*) & $10: 40-15: 50$ & $10: 40-16: 00$ & $11: 00-16: 00$ & $11: 00-15: 40$ & $11: 00-16: 00$ & $11: 00-15: 40$ & 13:20-19:00 & 11:00-16:00 & $11: 00-15: 50$ \\
\hline Descriptor & $\begin{array}{l}\text { Wind shear in } \\
\text { BL }\end{array}$ & $\begin{array}{l}\text { Moisture above, } \\
\text { drizzling }\end{array}$ & $\begin{array}{l}\text { Moisture above, } \\
\text { drizzling }\end{array}$ & $\begin{array}{l}\text { Decoupled, } \\
\text { wind shear in } \\
\text { BL, cirrus }\end{array}$ & $\begin{array}{l}\text { Double cloud } \\
\text { layer, cirrus }\end{array}$ & Typical & Typical & Typical & Typical \\
\hline
\end{tabular}

* Local time: UTC -4

in Sect. 3. In Sect. 4 we investigate the BL vertical structure. The temporal variation of BL structure is provided in Sect. 5 followed by the variations of cloud and aerosol properties in Sect. 6. Section 7 summarizes the general features of the $\mathrm{BL}$, cloud, and aerosol over the near-coastal region in the SE Pacific.

\section{Data and methods}

\subsection{Aircraft data}

The CIRPAS Twin Otter aircraft completed 19 flights in the vicinity of Point Alpha $\left(20^{\circ} \mathrm{S}, 72^{\circ} \mathrm{W}\right)$ off the coast of Northern Chile from 16 October to 13 November 2008. Because cloud and aerosol probe data failed on one of those flights (5 November), we only include observations from the other 18 flights in this paper. Each flight had a duration of 4.5 to $5.5 \mathrm{~h}$ and included at least two soundings and several 10 min horizontal legs near the ocean surface, below the cloud, near the cloud base, within the cloud, near the cloud top, and above the inversion. Fifteen of the flights started around 11:00 UTC (07:00 Local Time, LT), with the first sounding made around 12:00 UTC (08:00 LT), while the other three flights took off about $3 \mathrm{~h}$ later (see Table 1 for a list of the flights).

The data from the onboard instruments were processed and quality-controlled to provide standard meteorological turbulence, aerosol, cloud, and precipitation observations. The measured and derived variables obtained at a frequency of $10 \mathrm{~Hz}$ used in this study include wind speed, wind direction, vertical velocity, air temperature, air density, pressure, mixing ratio, IR sea surface temperature (SST), and cloud liquid water content (LWC) from the PVM-100 probe (Gerber et al., 1994). The cloud and aerosol data obtained at $1 \mathrm{~Hz}$ include accumulation mode aerosol (size range: $0.1-2 \mu \mathrm{m})$ concentration $\left(N_{\mathrm{a}}\right)$ from the Passive Cavity Aerosol Spectrometer Probe (PCASP), $N_{\mathrm{d}}$ from the measurements by the Cloud, Aerosol and Precipitation probe (CAS), cloud condensation nuclei $(\mathrm{CCN})$ from the $\mathrm{CCN}$ Spectrometer, effective radius of cloud droplets $\left(R_{\mathrm{e}}\right)$ from the PVM-100 probe, and drizzle water content from the Cloud Imaging Probe (CIP). Uncertainties for aerosols and cloud droplet concentrations measured by these probes are estimated to be within $15 \%$ in the sample flow. Descriptions of the instruments used on the Twin Otter for these measurements are described in Zheng et al. (2010) and Wood et al. (2011). Because the total water mixing ratio $\left(q_{\mathrm{t}}\right)$ and the liquid water potential temperature $\left(\theta_{1}\right)$ are conserved during adiabatic processes, we calculated these two variables from the mixing ratio, $\mathrm{LWC}$, temperature and pressure to estimate the BL structure in the next sections.

\subsection{Reanalysis data, satellite measurements, and ra- diosonde data}

Previous studies suggest that large-scale dynamic forcing impacts the Sc properties on both the inter-seasonal and synoptic time-scales (Klein and Hartmann, 1993; Rozendaal and Rossow, 2003). The large-scale datasets, including meteorological reanalyses and satellite observations, along with soundings launched in the nearby region, provide a comprehensive data supply for exploring the large-scale background of the BL at Point Alpha.

We adopt the reanalysis of meteorological observations from the National Centers for Environmental Prediction (NCEP) /NCAR Reanalysis Project (NNRP, Kistler et al., 2001) to study the sea level pressure and the 700-hPa geopotential height over the large region $\left(50^{\circ} \mathrm{W}-95^{\circ} \mathrm{W}, 0^{\circ}-45^{\circ} \mathrm{S}\right)$. The resolution of the NCEP NNRP data is $2.5^{\circ} \times 2.5^{\circ} \times 17$ pressure levels and this data product is available at $6 \mathrm{~h}$ intervals. The resolution of this product is suitable for evaluating the large-scale patterns of sea level pressure and 700-hPa geopotential height. The same analyses with the ECMWF Interim reanalysis indicate that the results are insensitive to the different reanalysis products.

Radiances from the Tenth Geostationary Operational Environmental Satellite (GOES-10) were used to retrieve cloud properties at $4-\mathrm{km}$ resolution with the methods of Minnis et al. (2011b) for the area $\left(75.75^{\circ} \mathrm{W}-70.75^{\circ} \mathrm{W} 23.75^{\circ} \mathrm{S}-\right.$ $16.25^{\circ} \mathrm{S}$ ) in the vicinity of Point Alpha during VOCALSREx. Wood et al. (2011) provide further description and examples of the GOES VOCALS-Rex retrievals. Cloud 

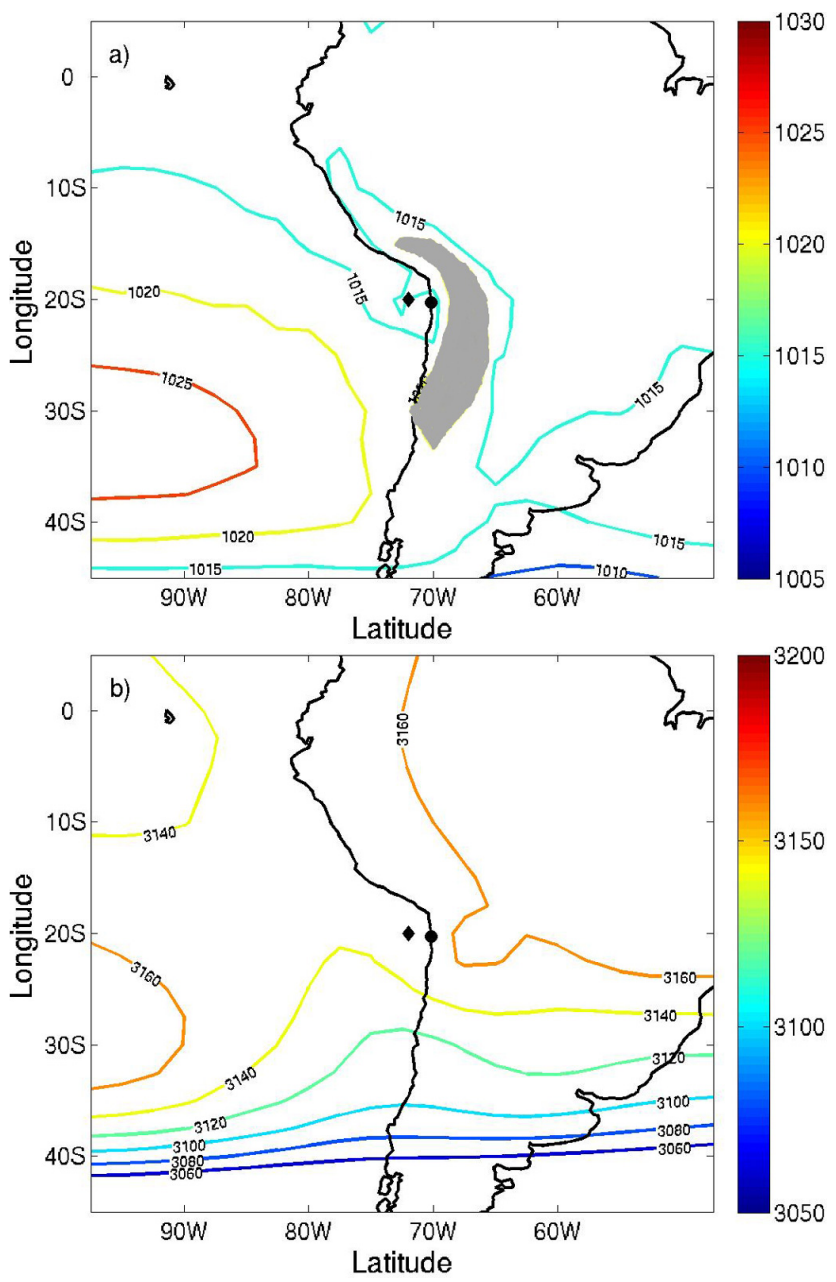

Fig. 1. (a) Composite Sea Level Pressure (16 October-13 November 2008). The contours are every $2 \mathrm{hPa}$. The Andes region is shaded to avoid the artificially high sea level pressure region due to the high altitude; (b) Composite 700-hPa geopotential height. The contours are every $20 \mathrm{~m}$. The black diamond marks Point Alpha, and the black dot indicates the location of Iquique. The coastal outline is shown as a black solid line.

properties were also retrieved from 1-km Terra MODerateresolution Imaging Spectroradiometer (MODIS) data using the same algorithms applied to the GOES-10 data (Minnis et al., 2011a). In addition, the Quick Scatterometer (QuikSCAT) L3 data provides $0.25^{\circ} \times 0.25^{\circ}$ resolution surface wind twice per day. The QuikSCAT surface wind field is used to estimate the average surface divergence at Point Alpha.

During VOCALS-REx an NCAR/EOL GPS Advanced Upper-Air Sounding (GAUS) system located in Iquique, Chile $\left(70.1^{\circ} \mathrm{W}, 20.3^{\circ} \mathrm{S}\right)$ launched Vaisala RS92 radiosondes 6 times per day. This radiosonde delivers high quality wind measurements, pressure, temperature, and humidity measurements. We adopt the radiosonde data as a supplement to describe the BL structure on the coast and compare it with that from the Point Alpha aircraft observations. Because of the diurnal cycle of continental $\mathrm{BL}$ and the direct influence of the Andes, the BL involves more complicated processes at this on-shore location, especially during the daytime. Although the radiosonde data have no liquid water information, the satellite retrievals indicate that the mean LWP over this near-coastal region is less than $30 \mathrm{~g} \mathrm{~m}^{-2}$ during the observations, as will be shown in Sect. 3. We assume that ignoring the contribution of liquid water to total water mixing ratio will not change the mean BL thermodynamic structure. Therefore, the potential temperature $(\theta)$ and water vapor mixing ratio $(q)$ calculated from the radiosonde data represent the BL thermodynamic structure.

\subsection{Back-trajectories}

To help establish the history of the air masses sampled by the aircraft, we use the Hybrid Single Particle Lagrangian Integrated Trajectory Model (HYSPLIT, Draxler and Rolph, 2011) to calculate back trajectories starting at Point Alpha. HYSPLIT can be set up to compute two-dimensional and three-dimensional parcel trajectories with a simple advection calculation. The input meteorological gridded data is the NCEP Global Data Assimilation System (GDAS) data with $1^{\circ} \times 1^{\circ}$ resolution. For each flight, two-dimensional parcel trajectories starting at the 500-m level (within the BL) and three-dimensional parcel trajectories staring at the 2000-m level (free atmosphere) are calculated for $48 \mathrm{~h}$ prior to the flight time.

\section{General synoptic conditions and variations}

\subsection{Synoptic patterns from NCEP reanalysis}

A rough picture of the large-scale meteorological conditions over the study period is given by the composite fields of sea level pressure and 700-hPa geopotential height from NCEP reanalysis. The mean sea level pressure (Fig. 1a) from 16 October to 13 November 2008 was controlled by the strength and location of the subtropical high and a lowlevel trough that extended from the equator along the coast to $25^{\circ} \mathrm{S}$ east of the northeast part of the subtropical high. The low-level trough, the subtropical high system, and the topography along the coast interact to produce conditions and processes unique to the near-coastal area (Garreaud and Muñoz, 2004, 2005). The mean 700-hPa geopotential height (Fig. 1b) shows that a mid-latitude trough reached $20^{\circ} \mathrm{S}$ between the subtropical high and Point Alpha. This indicates that the study region was influenced by the subtropical high system, and the mid-latitude trough.

Since this study occurred during the local austral spring season, the daily sea level pressure fields (not shown here) show that, the SE Pacific high system was strongest during the first several days (16 October-18 October), with the $1020-\mathrm{hPa}$ isobar extending over the ocean area south 

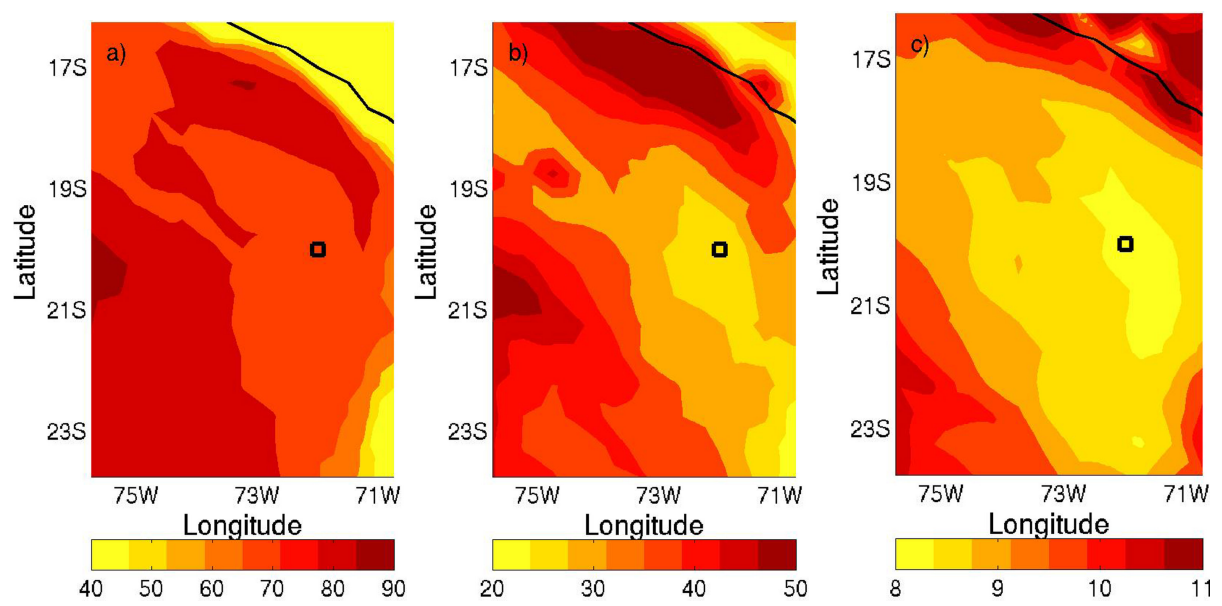

Fig. 2. The average fields of (a) low cloud amount (\%), (b) LWP $\left(\mathrm{g} \mathrm{m}^{-2}\right)$, (c) $R_{\mathrm{e}}$ (micron) derived from GOES-10 data during the flight time (see Table 1). Point Alpha is marked as the blue square box.

of $20^{\circ} \mathrm{S}$. As the study progressed, the SE Pacific high system weakened and varied due to the mid-latitude wave activity. At the end of the study period, the $1020-\mathrm{hPa}$ isobar moved to the open ocean area south of $25^{\circ} \mathrm{S}$ and west of $80^{\circ} \mathrm{W}$. The day-to-day 700-hPa geopotential height (not shown here) exhibited patterns with troughs developing from the mid-latitudes extending to north of $25^{\circ} \mathrm{S}$ (29 October2 November, 13 November). Meanwhile the subtropical high was strong and occupied the region west of $80^{\circ} \mathrm{W}$. Therefore, the longitudinal component of the general flow over this region increased during these troughing periods.

\subsection{Composite cloud properties from satellite observations}

As noted in Sect. 2.1, every flight mission time was about 4.5-5.5 h (see Table 1). During the flight missions, the GOES-derived cloud properties were available every $30 \mathrm{~min}$. To estimate the mean conditions of the large-scale cloud background, we averaged the GOES-derived low cloud amount (\%), liquid water path (LWP; $\mathrm{g} \mathrm{m}^{-2}$ ), and $R_{\mathrm{e}}$ to a horizontal resolution of $0.5^{\circ} \times 0.5^{\circ}$ when the aircraft was flying.

During the flight observing times, the mean low cloud amount (Fig. 2a) around Point Alpha was around 70\%, which was about $10 \%$ lower than that over the open ocean west of $73^{\circ} \mathrm{W}$. The coastal region had less than $60 \%$ cloud amount except for a long narrow band extending from $\left(17^{\circ} \mathrm{S}\right.$, $\left.74^{\circ} \mathrm{W}\right)$ to $\left(19^{\circ} \mathrm{S}, 71.5^{\circ} \mathrm{W}\right)$ with cloud amounts $>80 \%$. A climatological study using 18 years of satellite measurements (O'Dell et al., 2008) shows that the cloud LWP over the coastal region exhibits a doubly peaked diurnal cycle in October, with peaks at 11:00 and 23:00 UTC (07:00 and 19:00 LT), the former of which is around the flight observing time. Therefore, the long narrow band with high cloud amounts and LWP mentioned above could be a part of the

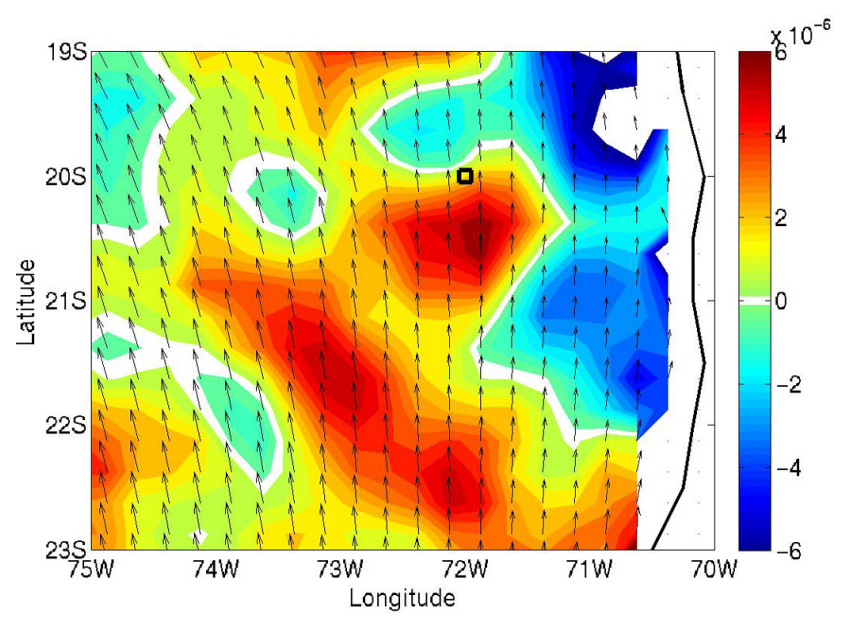

Fig. 3. The average surface wind (vectors) and divergence (color shading, increment $=2 \times 10^{-6} \mathrm{~s}^{-1}$ ) from QuikSCAT (16 October13 November 2008). Point Alpha is marked as the blue square box.

diurnal cycle and be linked to a wave of positive vertical velocity driven by the topography of the Andes moving from the coast of Peru in the late afternoon (Garreaud and Muñoz, 2004).

The GOES-10 average cloud LWP over Point Alpha during the observing time periods was about $27 \mathrm{~g} \mathrm{~m}^{-2}$, and it increased westward to the value of about $43 \mathrm{~g} \mathrm{~m}^{-2}$ around $75^{\circ} \mathrm{W}, 20^{\circ} \mathrm{S}$ (Fig. $2 \mathrm{~b}$ ). $R_{\mathrm{e}}$ over Point Alpha averaged less than $8.5 \mu \mathrm{m}$ (Fig. 2c), while $R_{\mathrm{e}}$ offshore was greater than $9.5 \mu \mathrm{m}$. The satellite retrievals during the observation time indicate that clouds over the study region were generally thin, bright and slightly broken compared with those in the adjoining areas possibly due to both meteorological and aerosol forcing. 


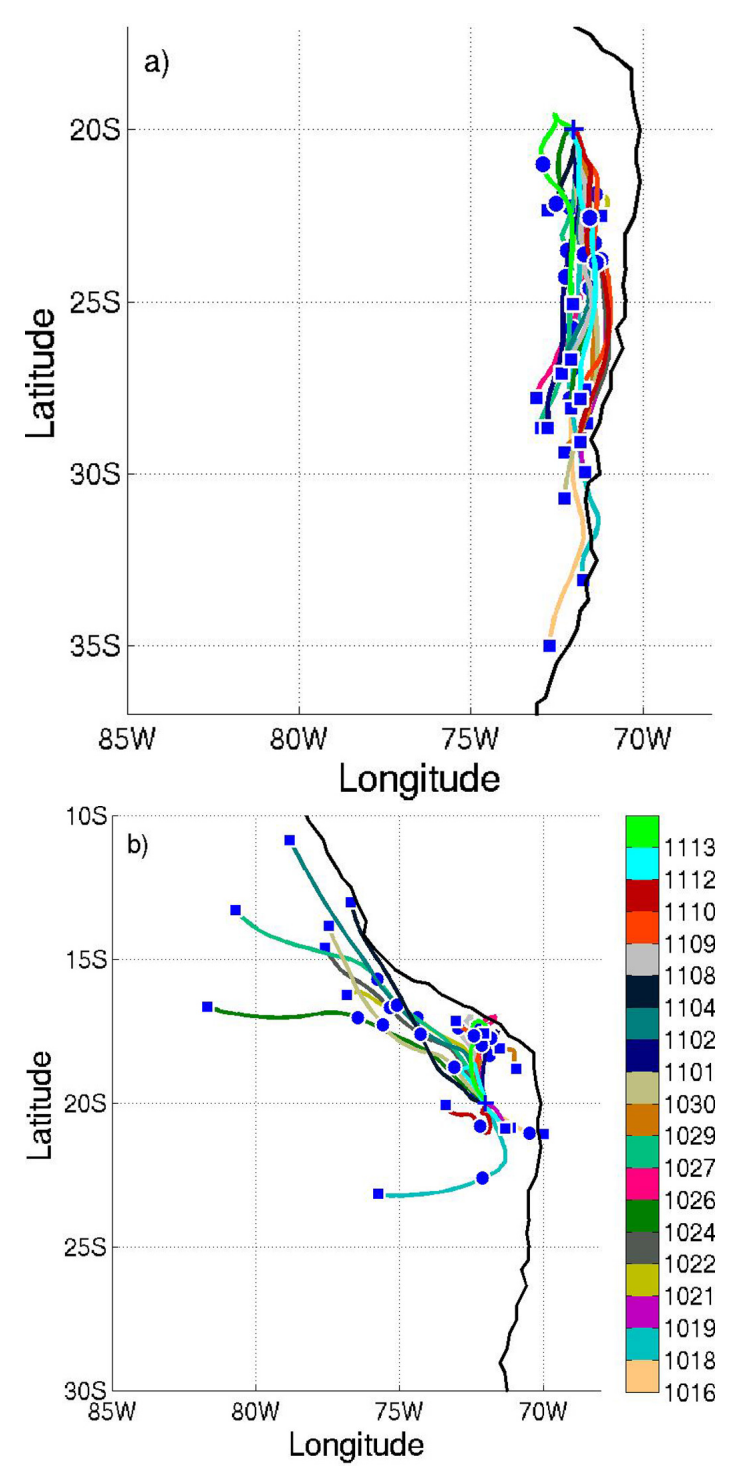

Fig. 4. (a) Two-dimensional isobaric back trajectories starting at $500 \mathrm{~m}$ from Point Alpha (Plus sign) for the 18 cases (color bar) with the 24 -h point (Blue Circle), and the 48-h point (Square); (b) threedimensional back trajectories starting at $2000 \mathrm{~m}$ from Point Alpha.

Because QuikSCAT winds over this study area were available two passes per day and the available time was random, it is impossible to estimate the surface divergence field during the aircraft mission time. Therefore, we averaged all 58 QuikSCAT surface wind passes over this study area from 16 October to 13 November 2008 to estimate the climatological features of the surface wind and divergence fields during VOCALS_REx. The average surface divergence (16 October-13 November) field from QuikSCAT winds (Fig. 3) reflects the complexity of this field in the nearcoastal regions and the sensitivity of the divergence calculations to the retrieved wind field, which is smoothed by time averaging. The entire indicated area was mainly controlled by divergence related to large-scale subsidence above the inversion, except in the narrow convergence zone along the coast east of Point Alpha due to the topography of the steep Andes as mentioned in a previous study (Rahn and Garreaud, 2010a). The average surface divergence at Point Alpha is about $3 \times 10^{-6} \mathrm{~s}^{-1}$. However, its variability might be large since Point Alpha is located near the transition zone between the typical subtropical Sc deck with strong surface divergence and the coastal area impacted by mesoscale processes such as gravity waves moving from the coastline (Rahn and Garreaud, 2010a). Further, since the QuikSCAT winds were available whenever the measurement swath of QuikSCAT covered this region, the composite surface wind and divergence fields include diurnal variations. The surface divergence from ECMWF Interim reanalysis with a horizontal resolution of $0.7^{\circ} \times 0.7^{\circ}$ is $1 \times 10^{-6} \mathrm{~s}^{-1}$.

\subsection{Back trajectories}

The back trajectories for the observed air masses (Fig. 4) at Point Alpha indicate that for the 18 flights the air masses within the BL (Fig. 4a) were mainly from the coastal regions south of Point Alpha, $48 \mathrm{~h}$ prior to observation. The air masses traveled toward Point Alpha over the ocean. The trajectories also indicate that most of the observed air masses stayed over the ocean for more than $24 \mathrm{~h}$ prior to the flights, and were advected by southerly to southwesterly flows. The air masses above the inversion (Fig. 4b) traveled longer distances and came from a wider variety of directions than those within the BL due to synoptic variability $48 \mathrm{~h}$ prior to the observations. The trajectory histories of the above-inversion air masses are as follows: north of Point Alpha along the coast of Peru during 4 flights; in the vicinity of Point Alpha during 7 flights; over the continent during 1 flight; over the ocean west of $77^{\circ} \mathrm{W}$ during 5 flights; and over the ocean and south of Point Alpha during only 1 flight. The flight observations (as shown in the next section) and the numerical simulations (Garreaud and Muñoz, 2005; Wang et al., 2011) indicate that the horizontal winds switch directions between the BL and above the inversion over the region due to the thermal wind balance and the blocking of the Andes. Overall, the back trajectories indicated that most of the above-inversion air masses moved in a direction opposite to those of the air masses within the BL.

\subsection{Synoptic variations}

Time evolution of sea level pressure and 700-hPa geopotential height around Point Alpha and Iquique indicate that the synoptic pattern over the near-coastal region did not vary as much as over the open ocean south of $25^{\circ} \mathrm{S}$ (Fig. 5). The NCEP sea level pressure at Point Alpha fluctuated between 1013 and $1018 \mathrm{hPa}$. The sea level pressure was also estimated from the aircraft 30-m level observations of pressure and virtual temperature on each day; these estimates tended 

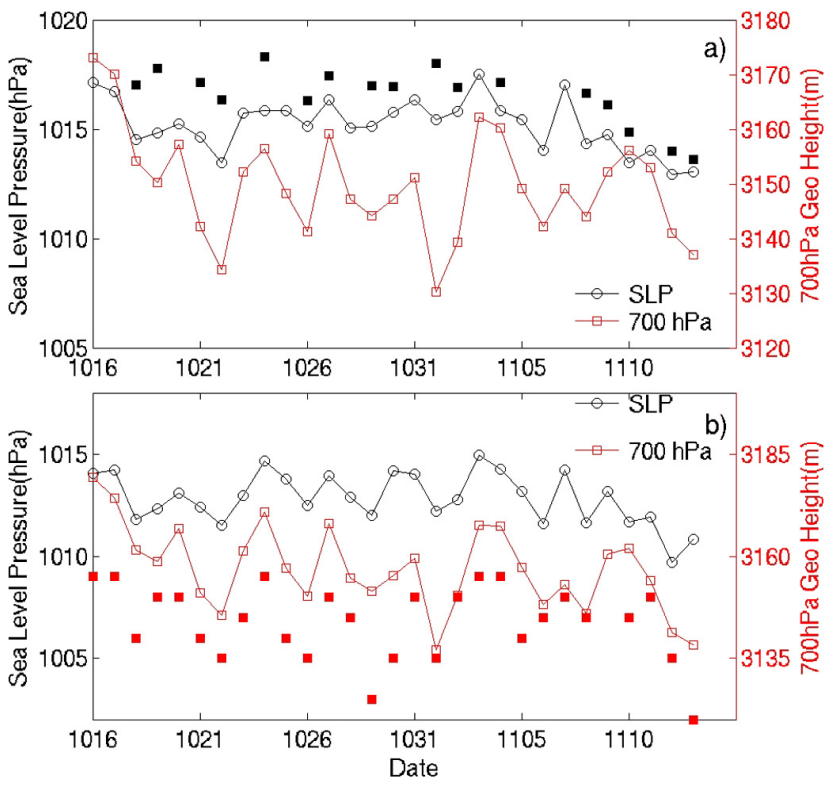

Fig. 5. Synthesis of sea level pressure and $700 \mathrm{hPa}$ geopotential height (a) at Point Alpha, and (b) at Iquique from NCEP reanalysis (12:00 UTC, open symbols) and radiosonde data ( 12:00 UTC, solid symbols).

to be about $3 \mathrm{hPa}$ higher than the NCEP values. Both showed the sea level pressure at Point Alpha gradually decreasing by about $5 \mathrm{hPa}$ by the end of the study period; however, the magnitude of the pressure change is not significant enough to be considered a seasonal signal because of the uncertainty of data and the potential synoptic variations. The NCEP 700$\mathrm{hPa}$ geopotential height at Point Alpha revealed a relatively constant patternern and varied from 3130 to $3180 \mathrm{~m}$ during the study period. Three 700-hPa geopotential height minima occurred on 22 October, 1 November, and 13 November. Meanwhile, the NCEP 700-hPa geopotential height at Iquique showed the same minima on the same days, which might be linked to midlevel troughs. Comparing these results with the 700-hPa geopotential height calculated from the Iquique radiosonde measurements, the NCEP 700-hPa geopotential height was about $25 \mathrm{~m}$ higher in October, and the bias clearly decreased in November. The synoptic evolution over this region altered the BL depth, the low-level wind, and the moisture properties, which will be discussed in Sect. 4.

\section{Boundary layer vertical structure}

\subsection{Thermodynamic profiles}

The typical Sc topped BL is well mixed and capped by a strong inversion (Albrecht et al., 1988). Previous studies have revealed that the inversion height $\left(z_{\mathrm{i}}\right)$ could be an important indicator of the structure of the BL in terms of de-
Table 2. Mean values of boundary layer from VOCALS Twin Otter.

\begin{tabular}{ll}
\hline Project & VOCALS Twin Otter \\
\hline Location & $20^{\circ} \mathrm{S} 72^{\circ} \mathrm{W}$ \\
Time & 16 Oct-13 Nov \\
Sc Regime & SE Pacific coastal region \\
$z_{\mathrm{i}}(\mathrm{m})$ & $1140 \pm 120$ \\
$\bar{\theta}_{\mathrm{l}}(\mathrm{K})$ & $289.5 \pm 1.2$ \\
$\Delta \theta_{\mathrm{l}}(\mathrm{K})$ & $11.8 \pm 1.9$ \\
$q_{\mathrm{t}}\left(\mathrm{g} \mathrm{kg}^{-1}\right)$ & $7.2 \pm 0.5$ \\
$\Delta q_{\mathrm{t}}\left(\mathrm{g} \mathrm{kg}^{-1}\right)$ & $-5.2 \pm 2.2$ \\
$\alpha_{\theta}$ & $0.14 \pm 0.09$ \\
$\alpha_{q}$ & $0.08 \pm 0.06$ \\
$\omega_{\mathrm{e}}\left(\mathrm{mm} \mathrm{s}^{-1}\right)$ & $2.0 \pm 1.4$ \\
$F_{\mathrm{L}}\left(\mathrm{W} \mathrm{m}{ }^{-2}\right)$ & $48.5 \pm 15.5$ \\
$F_{\theta}\left(\mathrm{W} \mathrm{m}^{-2}\right)$ & $7.1 \pm 2.5$ \\
$F_{\theta \mathrm{v}}\left(\mathrm{W} \mathrm{m}{ }^{-2}\right)$ & $9.7 \pm 2.7$ \\
$\mathrm{SST}\left({ }^{\circ} \mathrm{C}\right)$ & $18 \pm 1.0$ \\
\hline
\end{tabular}

coupling, cloud cover, etc. (Albrecht et al., 1995b). However, excluding the variation of $z_{\mathrm{i}}$ could help better estimate the composite thermodynamic and dynamic structures within the BL. In this study, $z_{\mathrm{i}}$ is quantified as the height at which the vertical gradient of $\theta_{1}$ is the largest. Figure 6 shows the profiles of $\theta_{\mathrm{l}}, q_{\mathrm{t}}$, and LWC using a height scale normalized by $z_{\mathrm{i}}$. In general, the profiles of $\theta_{\mathrm{l}}$ and $q_{\mathrm{t}}$ show a well-mixed BL capped by a sharp inversion during most of the flights. Within the BL $\theta_{\mathrm{l}}$ was about $289 \mathrm{~K}$ and the change across the inversion (denoted by $\Delta \theta_{1}$ ) ranged from 10 to $17 \mathrm{~K}$. The average $q_{\mathrm{t}}$ within the boundary layer was about $7.6 \mathrm{~g} \mathrm{~kg}^{-1}$ and the change across the inversion (denoted by $\Delta q_{\mathrm{t}}$ ) varied from +2 to $-8 \mathrm{~g} \mathrm{~kg}^{-1}$ (Table 2). During most of the flights $q_{\mathrm{t}}$ decreased sharply above the inversion. However, during two of the flights (1-2 November), $\Delta \theta_{1}$ was relatively small, and $q_{\mathrm{t}}$ increased above the inversion due to a moist layer above the inversion related to the synoptic system discussed above. The soundings launched at Iquique also captured the moist layer above the inversion from 31 October to 8 November (Fig. 7a) and the time-height diagram of the meridional winds at Iquique (not shown) indicate a clear southerly wind above the inversion around the similar period. The enhanced southerly wind from 31 October to 8 November combined with the 700-hPa geopotential height minima on 1 November and the following increasing (Fig. 5) may be due to synoptic systems that passed by and modified the flow pattern in this region. The time-height diagram of the potential temperature at Iquique (Fig. 7b) shows that the BL depth varied between $700 \mathrm{~m}$ and $1400 \mathrm{~m}$ over the course of the observation period.

To quantify how well mixed the BL was, we calculated the decoupling parameters $\alpha_{q}$ and $\alpha_{\theta}$ (Wood and Bretherton, 2004), which measure the relative difference between the surface and the upper part of the BL. 

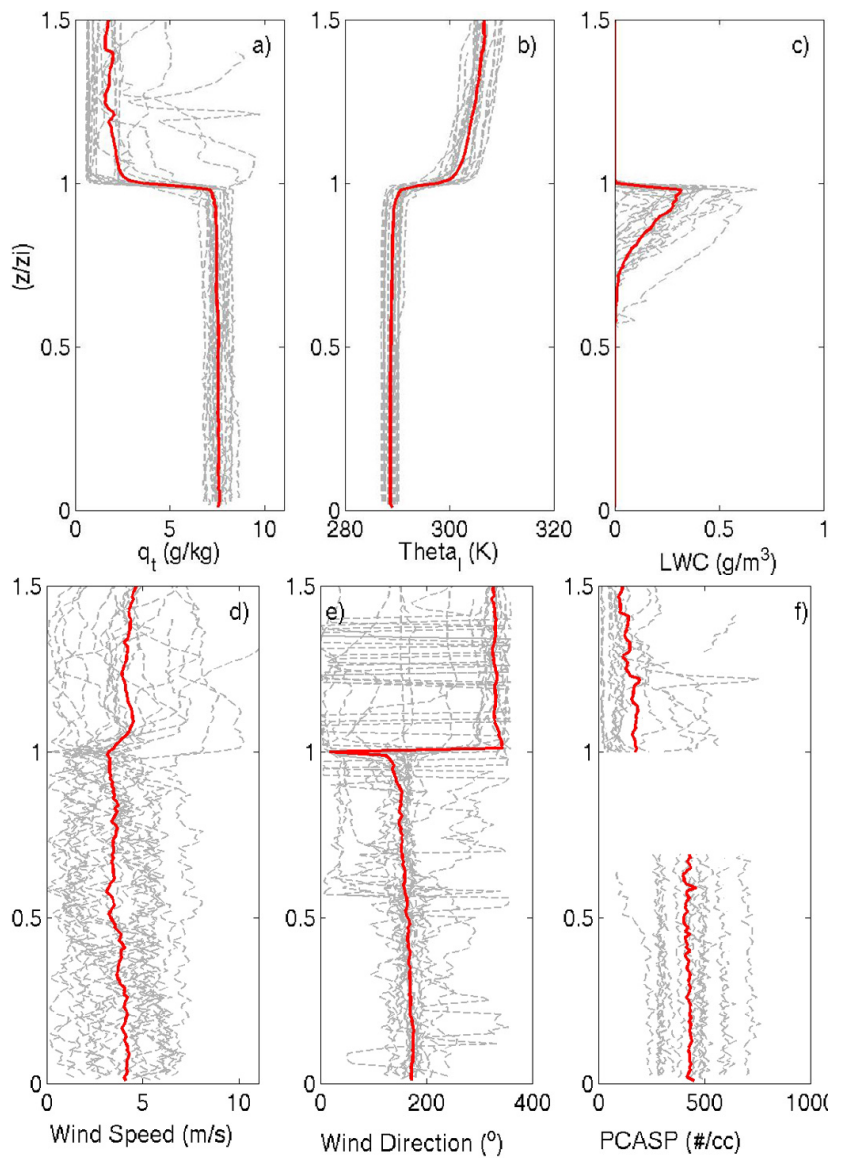

Fig. 6. Profiles scaled by the PBL heights. (a) total-water mixing ratio $\left(\mathrm{g} \mathrm{kg}^{-1}\right)$; (b) liquid water potential temperature (K); (c) LWC $\left(\mathrm{g} \mathrm{m}^{-3}\right)$; (d) wind speed $\left(\mathrm{m} \mathrm{s}^{-1}\right)$; (e) wind direction (degree), and (f) $N_{\mathrm{a}}$ from PCASP $\left(\# \mathrm{~cm}^{-3}\right)$ for all 18 flights. The gray lines indicate all individual flights, and the red solid lines show the composite soundings.

$$
\begin{aligned}
& \alpha_{\theta}=\frac{\theta_{l}\left(z_{\mathrm{i}}^{-}\right)-\theta_{\mathrm{l}}(0)}{\theta_{\mathrm{l}}\left(z_{\mathrm{i}}^{+}\right)-\theta_{\mathrm{l}}(0)} \\
& \alpha_{q}=\frac{q_{\mathrm{t}}\left(z_{\mathrm{i}}^{-}\right)-q_{\mathrm{t}}(0)}{q_{\mathrm{t}}\left(z_{\mathrm{i}}^{+}\right)-q_{\mathrm{t}}(0)}
\end{aligned}
$$

Where $z_{\mathrm{i}}^{+} / z_{\mathrm{i}}^{-}$is the level $25 \mathrm{~m}$ above/below the inversion, $\theta_{\mathrm{l}}(z)$ and $q_{\mathrm{t}}(z)$ are $\theta_{\mathrm{l}}$ and $q_{\mathrm{t}}$ at $z, \theta_{\mathrm{l}}(0)$ and $q_{\mathrm{t}}(0)$ are at the surface.

If these values are close to zero, the $\mathrm{BL}$ tends to be completely well-mixed. However, the BL is not always completely well-mixed due to solar radiation, drizzle, and BL deepening. Previous observations (e.g., Albrecht et al., $1995 b)$ suggest that if $\alpha_{q}$ exceeds a certain value $(\sim 0.3)$, which indicates that the upper part of the BL is clearly drier than the lower BL, the BL is decoupled. Thus the Sc layer may breakup and transition to trade wind cumulus conditions.
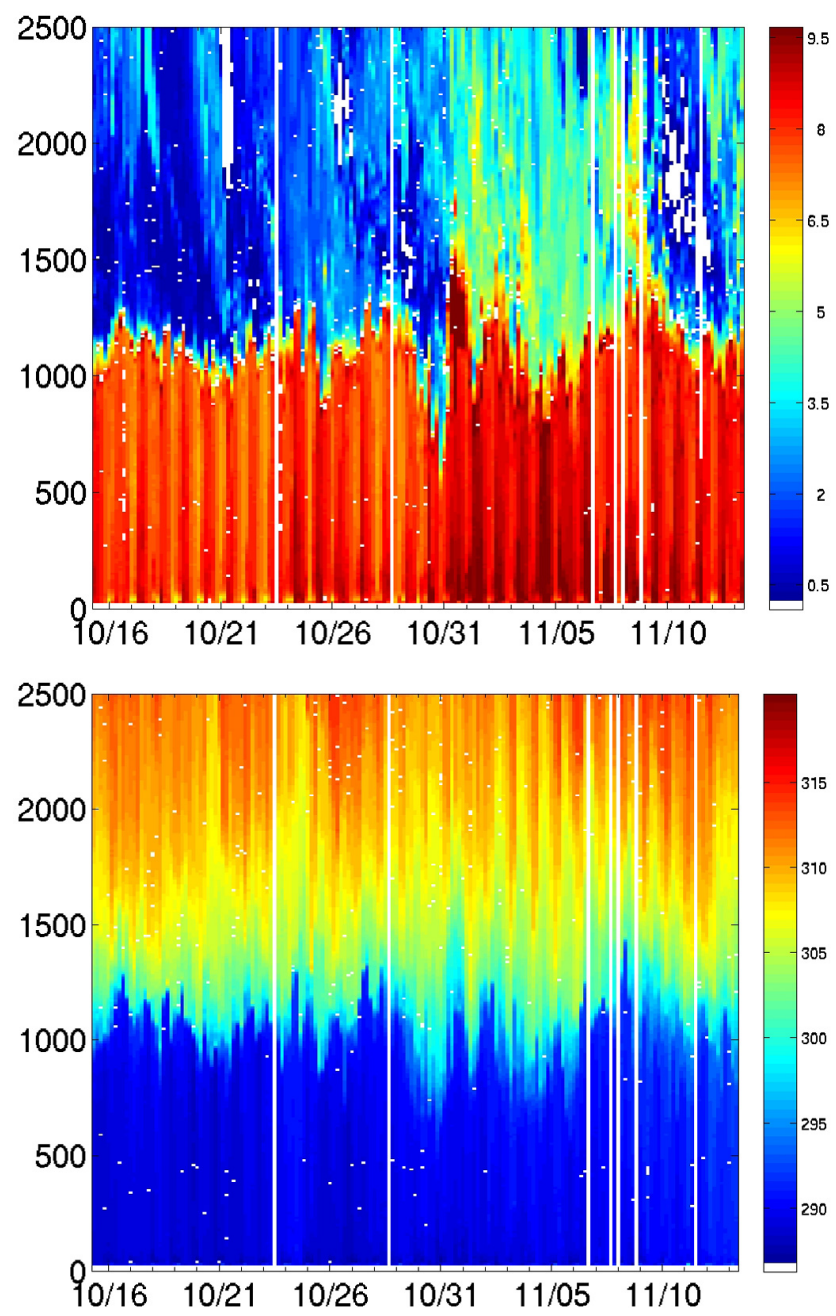

Fig. 7. Time-height section of (top) mixing ratio $\left(\mathrm{g} \mathrm{kg}^{-1}\right)$ and (bottom) potential temperature $(\mathrm{K})$ from the soundings launched at Iquique during VOCALS-REx.

Values of $\alpha_{q}$ and $\alpha_{\theta}$ from each flight sounding were calculated and their respective averages are $0.08 \pm 0.06$ and $0.14 \pm$ 0.09 , which are within the regime of "well-mixed". The results imply that for most of this season the BL over Point Alpha was well-mixed $\left(\alpha_{q}<0.1\right.$ and $\left.\alpha_{\theta}<0.15\right)$, except for 29 October, 1-2 November, 4 November and 8 November. On 29 October, 4 November, and 8 November, the BL was decoupled and some small cumulus developed below the Sc layer as indicated by the LWC profiles and the flight reports. Because of the synoptic forcing (1 November and 2 November, Fig. 6), the air above the inversion was no longer dry. On 1 November, an $\alpha_{\theta}$ of 0.42 reflects that drizzle processes enhanced the BL decoupling. The BL on 2 November with an $\alpha_{\theta}$ of 0.15 was less decoupled than that on 1 November. 

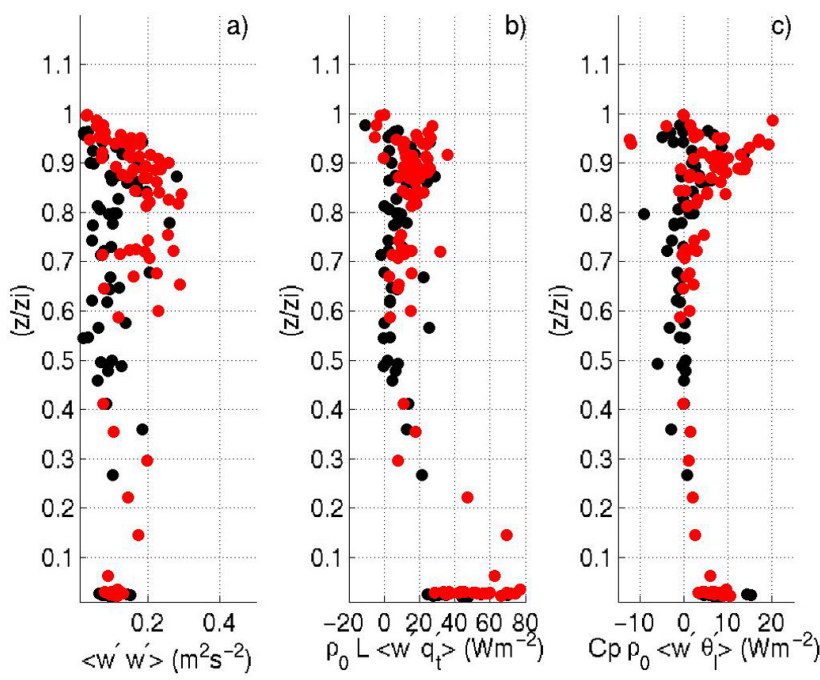

Fig. 8. (a) Vertical velocity variance $\left(\mathrm{m}^{2} \mathrm{~s}^{-2}\right)$, (b) total water flux $\left(\mathrm{W} \mathrm{m}^{-2}\right)$, and (c) liquid water potential temperature flux $\left(\mathrm{W} \mathrm{m}^{-2}\right)$ vs. normalized height calculated from all the flight legs for the 18 flights. Red solid symbols (10 flights) are the typical well-mixed boundary layer, non-drizzling Sc discussed in Zheng et al. (2010), black solid symbols ( 8 flights) are the cases with complications involving strong wind shear within the BL, moist layers above the inversion, strong decoupled BL with cumulus below Sc.

\subsection{Wind profiles}

The vertical profiles of the horizontal wind are shown in Fig. 6d-e. On most of the flight days, the wind speed and wind direction were nearly constant within the BL. The wind speed within the BL ranged between 1 and $7 \mathrm{~m} \mathrm{~s}^{-1}$ with an average value of $\sim 4 \mathrm{~m} \mathrm{~s}^{-1}$, which is lower than the BL wind speed $\left(>7 \mathrm{~m} \mathrm{~s}^{-1}\right)$ over the remote ocean during VOCALSREx (Bretherton et al., 2010; Wang et al., 2011). The wind speed at Point Alpha was also lower than the average BL wind speed of $7-8 \mathrm{~m} \mathrm{~s}^{-1}$ off the southern California coast during DYCOMS-II (Stevens et al., 2003). The wind direction below the inversion was mostly southerly $\left(150^{\circ}-\right.$ $\left.250^{\circ}\right)$, turning to northerly $\left(270^{\circ}-30^{\circ}\right)$ above the inversion. On 24 October and 4 November, the wind direction shifted sharply from southerly to northerly in the upper part of the BL. The wind direction on 30 October shifted from southerly to easterly in the upper part of the BL. The horizontal legs of observations within the $\mathrm{BL}$ on these three days showed the same wind patterns, which confirmed that the observed vertical wind shear within the BL was not due to sampling errors. This type of directional wind shear within the BL is not common and is probably linked to coastal processes such as the propagation of the upsidence wave (Garreaud and Muñoz, 2004; Rahn and Garreaud, 2010b).

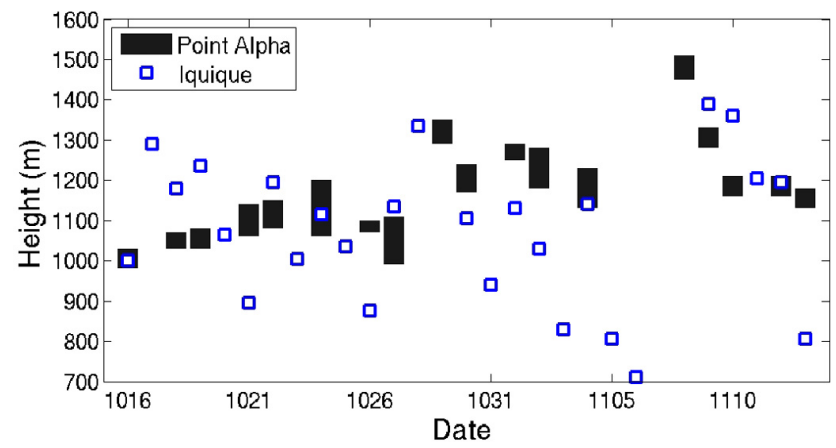

Fig. 9. Synthesis of the inversion level at Point Alpha from flight data, and at Iquique from radiosonde data. The open squares indicate the early morning soundings ( 07:00 UTC), and the black bar shows the inversion zone for each case.

\subsection{Turbulence structure}

On each flight day, several 10-min legs were flown at different levels. The turbulence and thermodynamic data gathered from these legs were processed to calculate the vertical distributions of leg-mean vertical velocity variance $\overline{w^{\prime} w^{\prime}}$, the total water flux $F_{q_{\mathrm{t}}}$, and the liquid water potential temperature flux $F_{\theta_{1}}$ for all of the flights (Fig. 8) from Eqs. (3)-(4):

$F_{q_{\mathrm{t}}}=L_{\mathrm{v}} \bar{\rho} \overline{w^{\prime} q_{\mathrm{t}}^{\prime}}$

$F_{\theta_{1}}=C_{\mathrm{p}} \bar{\rho} \overline{w^{\prime} \theta_{1}^{\prime}}$

where $L_{\mathrm{v}}=2.45 \times 10^{6} \mathrm{~J} \mathrm{~kg}^{-1}$ is the latent heat of vaporization at $20^{\circ} \mathrm{C}, \bar{\rho}$ is the air density, $C_{\mathrm{p}}=1005 \mathrm{~J} \mathrm{~kg}^{-1} \mathrm{~K}^{-1}$ is the specific heat of air.

The normalized cloud base heights were between 0.6 and 0.8 for most of the cases (Fig. 6c). In the lower part of the $\operatorname{BL}\left(z / z_{\mathrm{i}}<0.6\right), \overline{w^{\prime} w^{\prime}}$ ranged from 0.05 to $0.30 \mathrm{~m}^{2} \mathrm{~s}^{-2}$, and near the cloud base or within the cloud layer the values vary substantially. For most of the flights, $F_{q_{\mathrm{t}}}$ varied between 20 and $80 \mathrm{~W} \mathrm{~m}^{-2}$ near the surface, and then decreased with height in the lower part of the BL. $F_{\theta_{1}}$ ranged between -10 and $15 \mathrm{~W} \mathrm{~m}^{-2}$ below the cloud and generally decreased with height. Therefore, $F_{q_{\mathrm{t}}}$ tended to moisten the $\mathrm{BL}$ at a rate of $1.5 \mathrm{~g} \mathrm{~kg}^{-1} \mathrm{day}^{-1}$, and $F_{\theta_{1}}$ heated the lower BL at a rate of about $1 \mathrm{~K} \mathrm{day}^{-1}$. The southerly low-level wind along the coast brought cold and dry air from the south. Based on the soundings launched along the coastline during VOCALSREx (Rahn and Garreaud, 2010a), a rough estimate of the temperature tendency due to horizontal advection was about $-1 \mathrm{~K} \mathrm{day}^{-1}$, which could approximately balance the warming by the vertical sensible heat fluxes. Near the cloud top, $F_{\theta_{1}}$ reached about $20 \mathrm{~W} \mathrm{~m}^{-2}$ in some flights due to cloud top radiative cooling. Within the cloud layers, $F_{q_{\mathrm{t}}}$ increased and then decreased rapidly with height. The values reflect the considerable flight-to-flight diversity. The observed incloud vertical velocity variance $\left(\overline{w^{\prime} w^{\prime}}\right)$ at Point Alpha was 


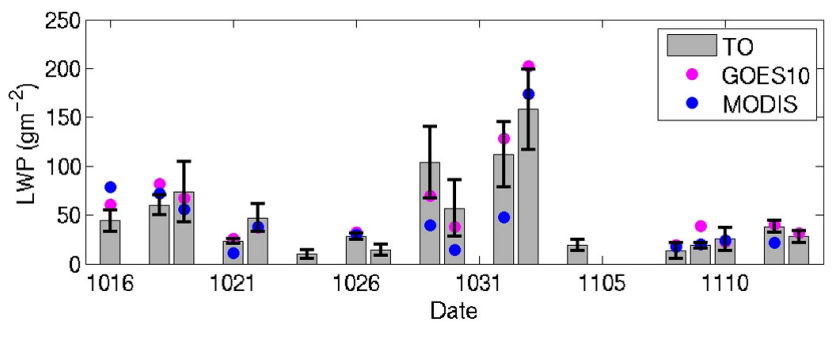

Fig. 10. LWP integrated from aircraft soundings on all flight days. The estimated errors in LWP from Eq. (5) are indicated by the error bars. Magenta symbols are GOES retrievals averaged for each entire flight mission over an area within a radius of $20 \mathrm{~km}$ of Point Alpha. Blue symbols are average Terra MODIS retrievals for a $0.5^{\circ}$ region centered on Point Alpha taken at between 14:20 and 15:50 UTC.

systematically lower than that over the remote ocean area $\left(80^{\circ} \mathrm{W}-85^{\circ} \mathrm{W}, 20^{\circ} \mathrm{S}\right)$, which had an estimated mean value of about $0.36 \mathrm{~m}^{2} \mathrm{~s}^{-2}$ during VOCALS-REx (Bretherton et al., 2010). The aircraft measurements of a nocturnal nondrizzling marine Sc off the southern California coast during the first research flight of DYCOMS-II (Stevens et al., 2005) also revealed a stronger turbulence structure than that at Point Alpha. In their observations, the in-cloud $\overline{w^{\prime} w^{\prime}}$ was larger than $0.4 \mathrm{~m}^{2} \mathrm{~s}^{-2}$, and the maximum of $0.5 \mathrm{~m}^{2} \mathrm{~s}^{-2}$ was near cloud base. The different measurements and calculation methods from their studies and this study, however, may partly affect the values as well.

\section{Temporal variation of BL structure}

\subsection{BL depth variation}

Figure 9 shows the time series of inversion height $z_{\mathrm{i}}$ measured from the aircraft soundings data at Point Alpha. It increased from about $1000 \mathrm{~m}$ at the beginning of the study period to about $1200 \mathrm{~m}$ by the end. On 29 October and 4 November, inversions at $1300 \mathrm{~m}$ and $1450 \mathrm{~m}$, respectively, were observed. The BLs on those days were decoupled and small cumuli were observed below the Sc layer. There was a transition zone at the top of the BL, where entrainment processes were critical to the growth of the BL, the evolution of cloud depth, etc. We call this the entrainment zone, and define it based on the soundings (air temperature, $q_{\mathrm{t}}$, LWC, etc.). The bottom of the entrainment zone is defined as the level where the soundings clearly started losing the BL feature and transiting to the free troposphere, while the top of the entrainment zone is the level where these soundings totally lose the BL features. The entrainment zone (Fig. 9) was less than $50 \mathrm{~m}$ thick at the beginning and the end of the study period indicating that the BL inversion is very sharp; however, there were 3 days $(24,27$ October and 4 November) when an entrainment zone thicker than $100 \mathrm{~m}$ was ob- served. The thicker entrainment zone reflects an interaction between the BL and the free air aloft that extended over a very large depth and can be linked to the strong vertical wind shear within the BL on 24 October and 4 November as mentioned before. On 27 October, the flight started around 15:00 UTC (11:00 LT), i.e., later than the usual 12:00 UTC (08:00 LT), which may also be a factor. The inversion levels from early morning soundings (07:00 UTC, 03:00 LT) launched at Iquique (Fig. 9), show that the BL structure at Iquique was more complicated than that at Point Alpha due to land surface and topography effects. The BL at Iquique showed double inversions on 5-6 days during the study, and thus the BL depth varied more significantly than that at Point Alpha. On average, $z_{\mathrm{i}}$ at Iquique was about $1070 \pm 190 \mathrm{~m}$, which was close to the BL depth at Point Alpha.

\subsection{Cloud LWP variation}

The average sounding of LWC from the PVM-100 probe was integrated to represent the cloud LWP. The LWP in this study was integrated with the average profile of LWC from two soundings on each day rather than with the 12:00 UTC (08:00 LT) soundings only (Zheng et al., 2010). Therefore, the LWP values in this study are slightly different from the values in Zheng et al. (2010). The LWC observations from the 10-min horizontal legs within the cloud layer provide the spatial distribution of LWC. We used the standardized differences $(\%)$ between the averaged LWC from the in-cloud $\operatorname{leg}\left\langle\operatorname{LWC}_{\operatorname{leg}}(z)\right\rangle$ and the sounding LWC at the same altitude $\mathrm{LWC}_{\text {profile }}(z)$ to estimate the uncertainty range of the LWP estimate (Fig. 10):

$\operatorname{error}(\%)=\frac{\left|\operatorname{LWC}_{\text {profile }}(z)-\left\langle\operatorname{LWC}_{\text {leg }}(z)\right\rangle\right|}{\operatorname{LWC}_{\text {profile }}(z)} \times 100$

The uncertainties associated with the cloud water variances along the in-cloud leg, the sloping profiles flown, etc. are not included in the error formula, which might increase the uncertainty of the LWP estimate in highly inhomogeneous cloud layers. The observed cloud LWP ranged from less than $20 \mathrm{~g} \mathrm{~m}^{-2}$ to about $180 \mathrm{~g} \mathrm{~m}^{-2}$. The GOES-derived cloud LWPs averaged over an area within a $20 \mathrm{~km}$ radius of the in situ aircraft observations locations and the $0.5^{\circ}$-average Terra LWPs over Point Alpha at $~ 15: 00$ UTC (11:00 LT) are generally close to those from the aircraft. This close correspondence further indicates that the observed clouds were nearly solid and homogeneous on most days during the aircraft observations, conditions for which the satellite retrievals perform best. The Terra LWP is less than the GOES average values on most days, primarily because the Terra measurements mostly occurred at the end of the flights when the clouds had thinned out. No Terra retrieval was obtained on 13 November. According to the GOES retrievals for all of the flights, the average LWP at 12:45 UTC (08:45 LT) was $62.0 \mathrm{~g} \mathrm{~m}^{-2}$ compared to 33.9 at $15: 30$ UTC (11:30 LT). For all 18 flights, the average in situ LWP was 

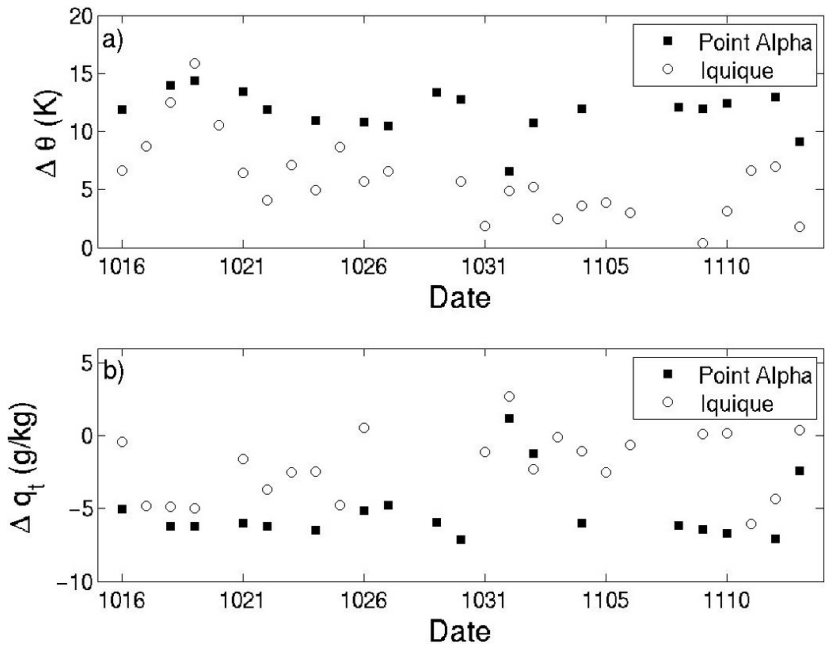

Fig. 11. (a) $\Delta \theta(\mathrm{K})$; (b) $\Delta q_{\mathrm{t}}\left(\mathrm{g} \mathrm{kg}^{-1}\right)$. The solid squares represent the values at Point Alpha measured by the aircraft, and the open circles donate the values at Iquique measured by the radiosonde system.

$48.5 \mathrm{~g} \mathrm{~m}^{-2}$. The GOES LWP values were, on an average flight day, $6.7 \pm 18.4 \mathrm{~g} \mathrm{~m}^{-2}$ greater than the in situ values and had a squared correlation coefficient $R^{2}=0.84$. The MODIS average is $6.3 \pm 27.4 \mathrm{~g} \mathrm{~m}^{-2}$ less than the in situ values with $R^{2}=0.59$. However, the MODIS average LWP is only $0.8+8.0 \mathrm{~g} \mathrm{~m}^{-2}$ less than the GOES averages over Point Alpha at the times of the Terra overpasses for all 17 days. For those data, $R^{2}=0.98$.

The highest cloud LWP values of $112 \pm 33$ and $158 \pm$ $41 \mathrm{~g} \mathrm{~m}^{-2}$, occurred on 1 November and 2 November, respectively, on which days a moist layer above the inversion moved to this study region (Fig. 7). The third highest LWP $\left(105 \pm 36 \mathrm{~g} \mathrm{~m}^{-2}\right)$ occurred on 29 October, when the BL was clearly decoupled and its depth reached $1300 \mathrm{~m}$. On the days with vertical wind shear within the BL (24 October and 4 November), the BL was decoupled with thin and broken Sc, and the cloud LWPs were $10 \pm 4$ and $19 \pm$ $6 \mathrm{~g} \mathrm{~m}^{-2}$, respectively. The cloud LWPs on the two decoupled days ( 8 November and 13 November) were $13 \pm 8$ and $28 \pm 6 \mathrm{~g} \mathrm{~m}^{-2}$, respectively. From Fig. 10, the cloud LWPs were about $50 \mathrm{~g} \mathrm{~m}^{-2}$ before 29 October when a synoptic system affected conditions at Point Alpha. From this point in time to 2 November the cloud LWP appears to be mainly controlled by synoptic disturbances.

\subsection{Inversion and surface conditions}

The inversion strength, $\Delta q_{\mathrm{t}}$ and $\Delta \theta_{\mathrm{l}}$, indicates the extent to which the BL can resist the entrainment of the dry, warm air from the free atmosphere aloft.

$$
\begin{aligned}
& \Delta \theta_{\mathrm{l}}=\theta_{\mathrm{l}}\left(z_{\mathrm{i}}^{+}\right)-\theta_{\mathrm{l}}\left(z_{\mathrm{i}}^{-}\right) \\
& \Delta q_{\mathrm{t}}=q_{\mathrm{t}}\left(z_{\mathrm{i}}^{+}\right)-q_{\mathrm{t}}\left(z_{\mathrm{i}}^{-}\right)
\end{aligned}
$$
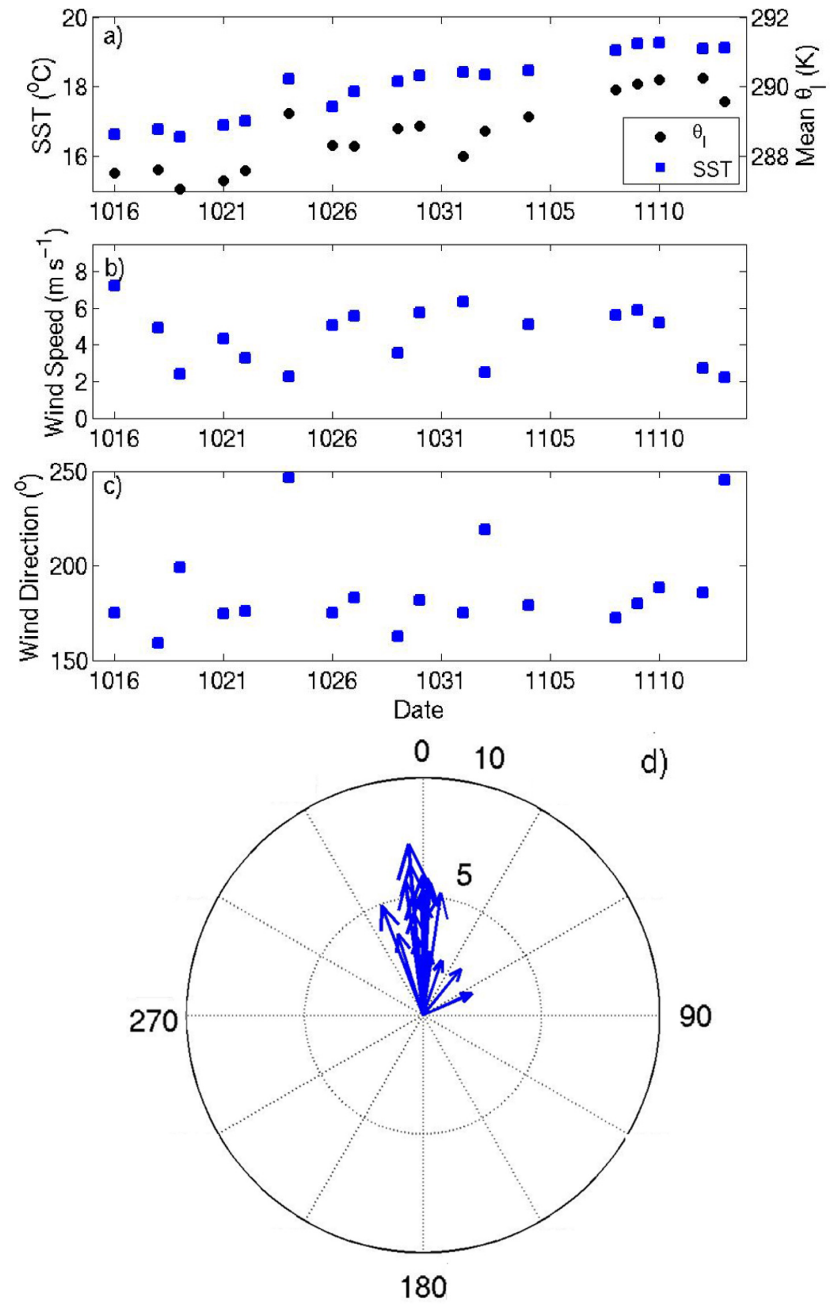

Fig. 12. (a) SST and BL-averaged $\theta_{1}$, (b) 30-m wind speed, (c) 30$\mathrm{m}$ wind direction, and (d) surface wind vectors from flight data.

The typical Sc-topped BL has a large inversion strength in terms of $\Delta q_{\mathrm{t}}$ and $\Delta \theta_{\mathrm{l}}$ (Albrecht et al., 1988; Serpetzoglou et al., 2008). Figure 11 shows that $\Delta \theta_{1}$ decreased to $8 \mathrm{~K}$ on 1 November, when the moist layer was observed above the inversion. From 4 November, $\Delta \theta_{1}$ was relatively consistent around $15 \mathrm{~K}$ until it decreased to around $12 \mathrm{~K}$ on 13 November, $\Delta q_{\mathrm{t}}$ was less than $-4.8 \mathrm{~g} \mathrm{~kg}^{-1}$ on most flight days except 1-2 November when a moist layer above the inversion moved to this location (as shown in Figs. 6-7). The inversion strength at Iquique appeared weaker than that at Point Alpha on almost all the days. From 31 October to 13 November the inversion strength at Iquique was clearly weaker than the earlier days of the study period, which is consistent with the water mixing ratio and the potential temperature pattern (Fig. 7).

SST (Fig. 12a) increased steadily from $16.5^{\circ} \mathrm{C}$ on $16 \mathrm{Oc}$ tober to $19.5^{\circ} \mathrm{C}$ on 13 November and the whole BL average $\theta_{1}$ increased in unison with the SST. We used monthly 
average SST data (1998-2008) from the Tropical Rainfall Measuring Mission (TRMM) Microwave Imager (TMI) to check the climatology of SST at Point Alpha. The seasonal cycle of the monthly SST increases from October to March. The climatological SST increase was about $1.1 \pm 0.4{ }^{\circ} \mathrm{C}$ from October to December at Point Alpha, which is less than the SST increase observed during the observational period. The relatively strong SST increase observed at Point Alpha during VOCALS-REx might be due to an inter-annual variation of SST over this region related to oceanic circulations. In terms of shorter temporal variability, the SST and BLaveraged $\theta_{1}$ on 24 October were $1.5^{\circ} \mathrm{C}$ warmer than the two days before and $1{ }^{\circ} \mathrm{C}$ warmer than the two days after it, probably because of some small-scale oceanic variations passing by Point Alpha. Based on the soundings, LWP, and satellite images, the cloud cover on 24 October was very thin and broken.

The wind speed and wind direction obtained from the 30-m level horizontal flight legs are shown in Fig. 12b-d. Consistent with the back trajectories and synoptic patterns discussed above, the surface wind was mainly southerly with a speed of $4 \mathrm{~m} \mathrm{~s}^{-1}$ on most of the flight days, except on 27 October, 2 November, and 13 November, when it was southeasterly with a speed of roughly $2 \mathrm{~m} \mathrm{~s}^{-1}$. The average surface wind speed from QuikSCAT at Point Alpha was $4.1 \pm 1.5 \mathrm{~m} \mathrm{~s}^{-1}$ and the wind direction was around $175^{\circ}$, which is consistent with the in situ observations.

On each flight day, the aircraft collected one or two 10-min legs at a height of $30 \mathrm{~m}$. We used the turbulence and thermodynamic data to estimate the latent heat flux $F_{\mathrm{L}}$, the sensible heat flux $F_{\theta}$, and the buoyancy flux $F_{\theta \mathrm{v}}$ (Table 2) directly from Eqs. (3)-(4) and Eq. (8):

$F_{\theta_{\mathrm{v}}}=C_{\mathrm{p}} \bar{\rho} \overline{w^{\prime} \theta_{\mathrm{v}}^{\prime}}$

where $\overline{w^{\prime} q^{\prime}}, \overline{w^{\prime} \theta^{\prime}}$, and $\overline{w^{\prime} \theta_{\mathrm{v}}^{\prime}}$ are the $30-\mathrm{m}$ level kinematic fluxes of moisture, heat and buoyancy, respectively. The average $F_{\mathrm{L}}$ was $48.5 \pm 15.5 \mathrm{~W} \mathrm{~m}^{-2}$, and the average $F_{\theta}$ and $F_{\theta \mathrm{v}}$ over the study period was $7.1 \pm 2.5 \mathrm{~W} \mathrm{~m}^{-2}$ and $9.7 \pm 2.7 \mathrm{~W} \mathrm{~m}^{-2}$, respectively.

\subsection{Entrainment rates}

The total water flux $\overline{w^{\prime} q_{\mathrm{t}}^{\prime}}$ from the 10-min legs near cloud top was used to calculate the entrainment rate $\left(\omega_{\mathrm{e}}\right)$ in this study. If the entrainment zone is thin enough, $\omega_{\mathrm{e}}$ can be estimated as:

$\omega_{\mathrm{e}}=-\overline{\frac{w^{\prime} q_{\mathrm{t}}^{\prime}}{\Delta q_{\mathrm{t}}}}$

We extrapolate $\overline{w^{\prime} q_{\mathrm{t}}^{\prime}}$ to the inversion according to the observational study of Gerber et al. (2005). The resulting uncertainty of the calculation can be about $50 \%$. The jump $\Delta q_{\mathrm{t}}$ was positive and $\overline{w^{\prime} q_{\mathrm{t}}^{\prime}}$ was positive on 1-2 November; therefore these two days were excluded from our cal- culation. The extrapolation method was failed on 30 October and 8 November because there were not enough flight legs near the cloud top on these two days. The maximum $\omega_{\mathrm{e}}$ is $3.7 \mathrm{~mm} \mathrm{~s}^{-1}$ and the minimum $\omega_{\mathrm{e}}$ is $0.5 \mathrm{~mm} \mathrm{~s}^{-1}$ on 13 November and 4 November, respectively. On the days with a large entrainment zone (24 October, 27 October, 4 November), the entrainment rates were not significantly larger than the average value. However, the LWC profiles show that drier and thinner cloud layers were observed on these days. The average $\omega_{\mathrm{e}}$ of $2.0 \pm 1.4 \mathrm{~mm} \mathrm{~s}^{-1}$ (Table 2) tends to be lower than that obtained using reanalysis and satellite observations (Wood and Bretherton, 2004). The relatively low $\omega_{\mathrm{e}}$ values are consistent with the relatively weak TKE observed at Point Alpha (Fig. 8).

Possible explanations for the relatively low $\omega_{\mathrm{e}}$ values in this study could be: (1) the observations during DYCOMSII were during nighttime, when the BL was deepening and thus the entrainment rate tended to be large (Stevens et al., 2003). (2) $\omega_{\mathrm{e}}$ in Wood and Bretherton (2004)'s study was derived from the balance between the divergence of $z_{\mathrm{i}}$ and large scale subsidence. The large scale subsidence $(D)$ at $z_{\mathrm{i}}$ can be loosely defined by divergence and inversion height: $w_{\mathrm{s}}\left(z_{\mathrm{i}}\right)=-D z_{\mathrm{i}}$. If we adopt the same calculation as Wood and Bretherton (2004) with the average divergence from QuikSCAT during the study period (Fig. 3), the average subsidence was about $3 \mathrm{~mm} \mathrm{~s}^{-1}$, which is greater than the average $\omega_{\mathrm{e}}$ in this study. Nonetheless, the lower entrainment rate calculated from the near cloud top fluxes compared with the $\mathrm{BL}$ at the remote ocean west of Point Alpha and the costal BL in the NE Pacific is consistent with the weaker turbulence in the BL discussed above.

\section{Aerosol and cloud properties}

For each flight, the average cloud droplet concentration $N_{\mathrm{d}}$ was calculated from the in-cloud legs where the cloud LWC was larger than $0.05 \mathrm{~g} \mathrm{~m}^{-3}$ and $N_{\mathrm{d}}$ exceeded $15 \mathrm{~cm}^{-3}$. We averaged the PCASP aerosol concentrations $N_{\mathrm{a}}$ during the legs above the inversion level to get the average $N_{\mathrm{a}}$ above the inversion, and averaged $N_{\mathrm{a}}$ during the legs below the cloud base where LWC was less than $0.05 \mathrm{~g} \mathrm{~m}^{-3}$ to get the mean $N_{\mathrm{a}}$ in the subcloud layer (Fig. 13). During the study period, the $\mathrm{CCN}$ Spectrometer constantly measured $\mathrm{CCN}$ at a supersaturation of $0.2 \%$ (denoted as $0.2 \% \mathrm{CCN}$ ) except on the first four flights, during which the CCN Spectrometer constantly measured $\mathrm{CCN}$ at a supersaturation of $0.5 \%$ (denoted as $0.5 \% \mathrm{CCN}$ ). To estimate the temporal variation of $\mathrm{CCN}$ at the same supersaturation level, we adjusted the observed $0.5 \% \mathrm{CCN}$ to $0.2 \% \mathrm{CCN}$ on the first four flights. On the first four flights, the CCN Spectrometer also measured $0.2 \%$ $\mathrm{CCN}$ on another channel for several short time intervals. We averaged the concentration difference between $0.2 \% \mathrm{CCN}$ and $0.5 \% \mathrm{CCN}$ when both channels were on. Although the aerosol properties revealed significant variability from day to 


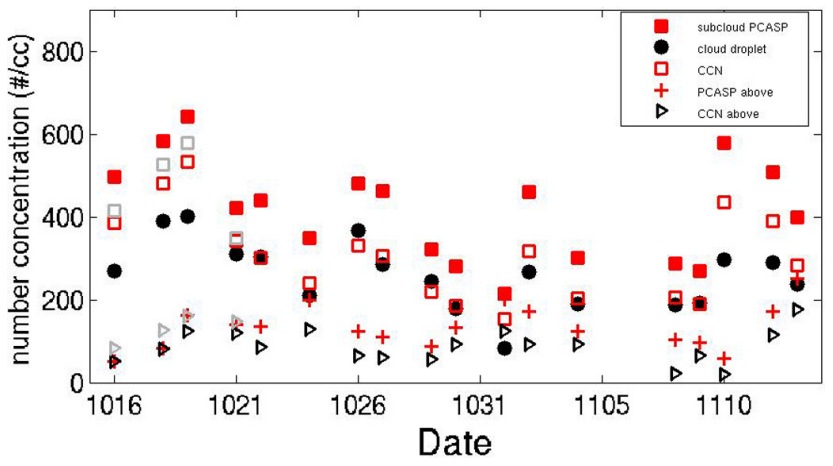

Fig. 13. Average subcloud aerosol (red solid square), above-cloud aerosol (red cross), sublcloud $0.2 \% \mathrm{CCN}$ (open red square), abovecloud $0.2 \% \mathrm{CCN}$ (black triangle), and cloud droplet (black dot) number concentrations on all flight days. The average $0.5 \% \mathrm{CCN}$ values for the first four flight days are marked as gray symbols.

day over the coastal region during VOCALS-REx (Allen et al., 2011), the same study also showed that the diurnal variability of aerosol composition can be neglected. We then assume that the aerosol chemical composition and size distribution did not vary significantly within each flight mission which lasted about four hours, and estimated the average $0.2 \% \mathrm{CCN}$ from the $0.5 \%$ values on days when the $0.2 \%$ values were not available continuously. The average $0.5 \%$ $\mathrm{CCN}$ values for the first four days were also indicated in the related figures. The highest in-cloud drizzle rates were observed on 1 November and 2 November, when the mean incloud drizzle water contents observed by the CIP probe were $0.0490 \mathrm{~g} \mathrm{~m}^{-3}$ and $0.0075 \mathrm{~g} \mathrm{~m}^{-3}$, respectively. The cloud LWP was highest on these two days as well (Fig. 10). On these two days, the peak observed in-cloud drizzle volume was $0.99 \mathrm{~g} \mathrm{~m}^{-3}$ and $0.22 \mathrm{~g} \mathrm{~m}^{-3}$, respectively. Very little drizzle was observed on the subcloud flight legs flown $100 \mathrm{~m}$ below the cloud base where small drizzle droplets might evaporate before reaching this level. The clouds at Point Alpha were non-drizzling or had very little drizzle compared with clouds over the open ocean during VOCALS-REx (Bretherton et al., 2010).

\subsection{Aerosol and cloud droplet number concentrations}

The average $N_{\mathrm{a}}$ above the inversion ranged between $50 \mathrm{~cm}^{-3}$ and $250 \mathrm{~cm}^{-3}$ and was lower than the average $N_{\mathrm{a}}$ below the cloud base on all flight days (Fig. 13). The above-inversion $N_{\mathrm{a}}$ was lower than $N_{\mathrm{d}}$ on most days except 1 November, during which the above-inversion $N_{\mathrm{a}}$ was close to the subcloud $N_{\mathrm{a}}$ and higher than $N_{\mathrm{d}}$. The vertical $N_{\mathrm{a}}$ profiles on 18 flights (Fig. 6f) also indicate diverse concentrations within and above the BL. On most flight days, the above-inversion $N_{\mathrm{a}}$ was lower than $150 \mathrm{~cm}^{-3}$, except for three soundings that captured high aerosol concentration plumes (24 October, 1 November, and 13 November). On those three days

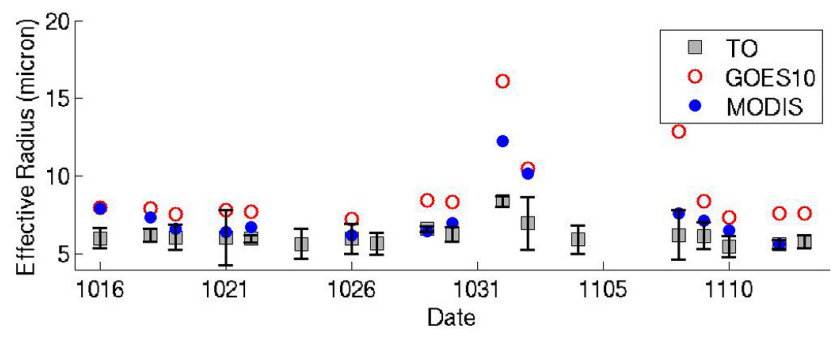

Fig. 14. $R_{\mathrm{e}}$ from the near-cloud-top legs on all flight days. The standard deviations are indicated as the error bars. Red symbols are GOES retrievals averaged over an area within a radii of $20 \mathrm{~km}$ of aircraft observations. Blue symbols are average Terra MODIS retrievals for a $0.5^{\circ}$ region centered on Point Alpha taken at between 14:20 and 15:50 UTC.

with high aerosol concentration plume above inversion, the above-inversion humidity was higher than the other days as well. The PCASP aerosol concentrations, typically comprising $80 \%$ of the total aerosol and those indicate the amount of aged aerosols (Pruppacher and Klett, 1997). Although on most days an above-inversion relative humidity that is much lower than that in the BL may cause the PCASP aerosol concentration to be poorly resolved due to a smaller dry size there, the above-inversion $0.2 \% \mathrm{CCN}$ shows the similar pattern as the PCASP values (Fig. 13). The low above-inversion $N_{\mathrm{a}}$ compared with the BL $N_{\mathrm{a}}$ implies that during VOCALSREx, the main aerosol source at Point Alpha was horizontal advection within the BL from the south, part of which might be entrained from above over further downwind days ago, rather than be entrained aerosol from above the inversion.

The time series of the subcloud $N_{\mathrm{a}}, 0.2 \% \mathrm{CCN}$ and $N_{\mathrm{d}}$ show large variations at Point Alpha during VOCALS-REx. The lowest $N_{\mathrm{a}}\left(250 \mathrm{~cm}^{-3}\right)$ occurred on 1 November, while the highest was close to $700 \mathrm{~cm}^{-3}$ on 19 October, which was nearly 2.5 times as large as the lowest value. The subcloud $N_{\mathrm{a}}$ were closely correlated to the temporal variation of $N_{\mathrm{d}}$ (Fig. 13) consistent with a strong coupling between the cloud and the subcloud layers in these nearly wellmixed conditions. The average $N_{\mathrm{d}}$ ranged between 80 and $400 \mathrm{~cm}^{-3}$, with a minimum of $84 \mathrm{~cm}^{-3}$ on 1 November. The subcloud $0.2 \% \mathrm{CCN}$ was almost equal to $N_{\mathrm{d}}$ on most of the flights. Based on a robust regression analysis, the relationship between $N_{\mathrm{d}}$ and $0.2 \% \mathrm{CCN}$ from 18 flights is $N_{\mathrm{d}}=4.6 \times \mathrm{CCN}^{0.71}$. Therefore, the power of $0.2 \% \mathrm{CCN}$ in the formula from 18 cases is close to the commonly assumed value of 0.7 (e.g., Feingold et al., 2001). Previous climatological studies (George and Wood, 2010; Painemal and Zuidema, 2010) of satellite-derived $N_{\mathrm{d}}$ indicated that the October $N_{\mathrm{d}}$ at Point Alpha was greater than $160 \mathrm{~cm}^{-3}$ and the difference between the maximum and the minimum $N_{\mathrm{d}}$ exceeded $150 \mathrm{~cm}^{-3}$.

We estimated the average $R_{\mathrm{e}}$ near cloud top using the same flight legs used to calculate entrainment rate. The average 


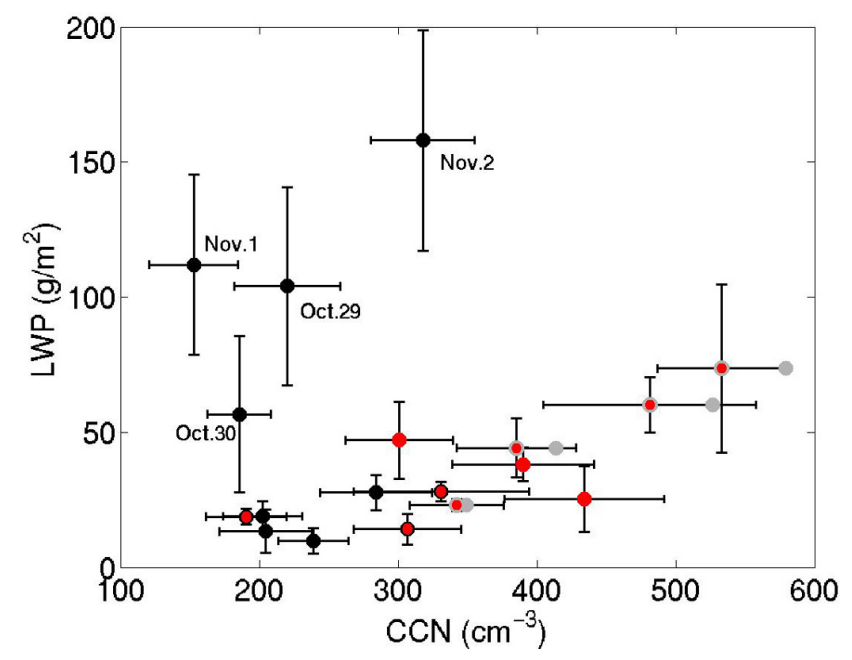

Fig. 15. LWP as a function of subcloud CCN concentrations for all flight days. The horizontal error bars through these symbols indicate the standard deviation of CCN. The uncertainty of the LWP denoted as the vertical bars. Red solid symbols are the typical well mixed boundary with non-drizzling Sc discussed in Zheng et al. (2010). The average $0.5 \% \mathrm{CCN}$ values for the first four flight days are indicated as the gray dots, and the corresponded $0.2 \%$ $\mathrm{CCN}$ values are marked as the red dots with gray edges.

$R_{\mathrm{e}}$ near cloud top varied between 5.5 and $8.5 \mu \mathrm{m}$ yielding a mean value of $6.2 \mu \mathrm{m}$ for all 18 flights. The Re values from the PVM-100 probe are estimated to be within about $15 \%$ of the actual value in the sample flow. The comparison of the in situ $R_{\mathrm{e}}$ near cloud top and the GOES-10 and Terra $R_{\mathrm{e}}$ (Fig. 14) indicates that the satellite derived $R_{\mathrm{e}}$ is systematically larger than the in situ observations. Moreover, the Terra values are all smaller than those from GOES. If the four days having cirrus contamination (see below) are excluded, the mean $R_{\mathrm{e}}$ values from GOES and MODIS, respectively, are $2.4 \pm 1.6$ and $1.1 \pm 1.2 \mu \mathrm{m}$ larger than their in situ counterparts. The corresponding values of $R^{2}$ are 0.91 and 0.82 for the satellite-in situ matches. The matched GOESderived LWP for these same 14 days exceeds the in situ values, on average, by only $3.4 \pm 19.9 \mathrm{~g} \mathrm{~m}^{-2}$, a difference of only $6 \%$. This indicates that the larger values of $R_{\mathrm{e}}$ on the cirrus-contaminated days contributed to the $\sim 7 \mathrm{~g} \mathrm{~m}^{-2}$ bias in the GOES LWP noted earlier.

The bias between the satellite retrievals and aircraft measurements may result since for the non-drizzling Sc cloud the cloud droplet size increases with height and the aircraft measurements were made about $50 \mathrm{~m}$ lower than the cloud top. However, the average from the vertical profiles was very close to the cloud-top values. The largest differences occurred on 24 and 27 October and on 1, 2, 4, and 8 November. The GOES retrievals were contaminated by overlying cirrus clouds on these days except for 1 and 2 November. The cirrus clouds lead to an overestimate of $R_{\text {e }}$. (e.g., Dong et al., 2002). Drizzle droplets on 1 and 2 November are the most likely explanation for the large discrepancies in $R_{\mathrm{e}}$ during those days. For drizzling conditions, in which the vertical structure of LWC can be quite different from the adiabatic case, $R_{\mathrm{e}}$ can increase downward below cloud top because the larger droplets sediment leaves a greater concentration of smaller droplets in the upper portion of the cloud. The $R_{\mathrm{e}}$ retrieved using a 3.9- $\mu \mathrm{m}$ radiance corresponds to an optical depth of 5 or more for $R_{\mathrm{e}}=12 \mu \mathrm{m}$ and 8 or more for $R_{\mathrm{e}}=8 \mu \mathrm{m}$, so it actually corresponds to a significant portion of the mass in the cloud and may not exactly correspond to $50 \mathrm{~m}$ below cloud top. As shown by Dong et al. (2002), $R_{\mathrm{e}}$ and LWC profiles are often non-adiabatic near the cloud top in stratus clouds so differences between $R_{\mathrm{e}}$ in the top $50 \mathrm{~m}$ and integrated over some depth in the cloud are not surprising. Furthermore, the droplets may be smaller at that level in the cloud because of entrainment of the overlying air.

The $R_{\mathrm{e}}$ differences between Terra and GOES-10 are mostly due to the time differences, noted earlier, that affect the LWP comparisons (e.g., Fig. 10). The mean GOES $R_{\mathrm{e}}$ at $12: 45 \mathrm{UTC}(08: 45 \mathrm{LT})$ is $9.2 \mu \mathrm{m}$ compared to $7.7 \mu \mathrm{m}$ at 15:30 UTC (11:30 LT) near the Terra overpass. Although the GOES results at the Terra overpass time essentially agree with the MODIS retrievals, there may also be some systematic algorithmic differences and spatial resolution effects that could contribute to those differences.

Despite the bias in the GOES retrievals of $R_{\mathrm{e}}$ relative the in situ measurements, the good correlation in $R_{\mathrm{e}}$ and agreement in LWP indicate that the satellite retrievals are providing a realistic representation of the variation in LWP and $R_{\mathrm{e}}$, at least, for unbroken adiabatic clouds. Since LWP is computed from the product of $R_{\mathrm{e}}$ and optical depth from the satellite data, an overestimate of $R_{\mathrm{e}}$ would imply an underestimate of cloud optical depth. Such an underestimate may be due to calibration biases or to biases in the retrieval algorithms. Either error source will require additional study.

\subsection{Cloud LWP and subcloud CCN concentrations}

Since all 18 flight cases at Point Alpha were with little- or non-drizzling marine Sc, the temporal variations of cloud LWP and aerosol concentrations at Point Alpha offered us an opportunity to study aerosol-cloud interactions in nondrizzling Sc at a fixed location. The cloud LWP as a function of subcloud $0.2 \% \mathrm{CCN}$ concentration for all flight cases is shown in Fig. 15. The synoptic variations, diurnal cycle of the $\mathrm{BL}$, and the other BL processes have to be taken into account when the cloud LWP-aerosol relationship is tested, as they can affect the cloud LWP (e.g., Albrecht et al., 1995b; Stevens and Feingold, 2009, etc.). Ten of those flights were made under similar meteorological conditions (Bold marked in Table 1 and highlighted in Fig. 15). The BL on those flight days were typically well-mixed, with solid non-drizzling Sc. The remaining eight flights involved complications as discussed in previous sections such as a moist layer above (12 November, 13 November), strong wind shear within the 
BL (24 October, 30 October, 4 November), strong decoupled BL with cumulus below the Sc layer (29 October, 4 November, 8 November). The four flights marked on Fig. 15 from 29 October to 2 November demonstrated an enhanced cloud LWP compared with the other days. One of the possible explanations could be the impact of a synoptic system related with the moist layer passing over this area. A positive relationship between the cloud LWP and aerosol in the typical well-mixed BL is observed in Fig. 16. However, this also shows that the meteorological factors and the BL processes that keep BL from being well-mixed can have large influences on the cloud LWP variation.

\section{Summary}

The Twin Otter aircraft performed 18 flights at Point Alpha during VOCALS-REx from 16 October to 13 November 2008. These observations provided a unique dataset for defining the characteristics of the near-coastal marine Sc and the BL off the coast of Northern Chile. This study used these in situ observations and meteorological reanalysis, radiosonde and satellite-derived data to study the BL, clouds, and aerosol variations at Point Alpha.

The results show that the BL at Point Alpha during VOCALS-REx was usually characterized by a typical Sctopped BL except when some synoptic systems and mesoscale processes affected this region. The BL depth was about $1140 \pm 120 \mathrm{~m}$ and the BL was well-mixed and capped by a very sharp inversion. The wind direction switched from southerly within the BL to northerly above the inversion. The surface wind speed was lower than that over the remote ocean west of Point Alpha due to the topography. On some flight days, wind shear appeared within the BL. The wind profile from the soundings are consistent with the average wind field from the horizontal flight legs, therefore, the observed vertical wind shear within the BL stayed constant throughout the flight mission. This phenomenon is rare and possibly due to the complex coastal processes. Compared with the $\mathrm{BL}$ depth west of Point Alpha over the remote ocean, the BL at Point Alpha was about 200-400 m shallower and more wellmixed (Bretherton et al., 2010). The BL depth was about $300 \mathrm{~m}$ higher than that over the coastal region in the NE Pacific (Stevens et al., 2003; Sharon et al., 2006). The surface wind and the surface fluxes at Point Alpha were weaker than those over the remote ocean and also weaker than the observations in the NE Pacific during DYCOMS-II. Turbulence in the near-coastal BL appeared to be weaker than that in the $\mathrm{BL}$ over the open ocean and the BL over the coastal region in the NE Pacific in terms of vertical velocity variance. The weaker turbulence in the BL at Point Alpha might contribute to the lower entrainment rate calculated from the near cloud top fluxes compared with the BL at the remote ocean west of Point Alpha and the costal BL in the NE Pacific (Bretherton et al., 2010; Stevens et al., 2003, 2005).
Throughout the study period, the BL evolved gradually with variations influenced by synoptic systems. From the end of October to the beginning of November, the cloud LWP was higher than the other days by around $40 \mathrm{~g} \mathrm{~m}^{-2}$ (Fig. 10). This is most likely due to an intense mid-latitude disturbance controlling the coastal area (Rahn and Garreaud, 2010b; Toniazzo et al., 2011). On 1 November and 2 November, a moist layer above the inversion moved over Point Alpha. The cloud LWP reached a maximum on these two days. The totalwater specific humidity above the inversion was larger than that within the BL. The inversion strength became significantly weaker on these two days and the BL was decoupled due to drizzle.

The accumulation mode aerosol and $0.2 \% \mathrm{CCN}$ measurements indicated $N_{\mathrm{a}}$ within the BL at Point Alpha varied between 250 and $700 \mathrm{~cm}^{-3}$ during VOCALS-REx. The main aerosol source at Point Alpha was the horizontal advection within the BL from south of Point Alpha. The average $N_{\mathrm{d}}$ ranged between 80 and $400 \mathrm{~cm}^{-3}$. This range was consistent with the satellite-derived $N_{\mathrm{d}}$. However, the GOES-derived cloud droplet $R_{\mathrm{e}}$ tended to be larger than that observed near cloud top, although the GOES-derived LWP was essentially the same as that determined from the aircraft vertical profiles of LWC. The aerosol and cloud LWP relationship reveals that during the typical well-mixed BL days the cloud LWP was positively correlated with the $0.2 \% \mathrm{CCN}$ concentrations. At the same time, meteorological factors and the decoupling processes have large influences on the cloud LWP variation as well. The aircraft flights lasted no more than five hours on each flight days and the time gap between two flights was generally longer than $24 \mathrm{~h}$. Thus, it was not possible to capture the continuous evolution of the cloud layer and the processes affecting the boundary layer structure and clouds at the time scales from hours to days, which could also be critical for the cloud LWP variation (e.g., Albrecht et al., 1995a; Sandu et al., 2008). Additionally, only 18 flights were completed, which is insufficient for finding a statistically significant correlation. The observations available are inadequate to full study the causes of the observed perturbation from the mixed layer state. Further modeling and diagnostic studies are required to fully explain the cloud LWP variation and its relationship with the aerosol variations at Point Alpha during VOCALS-REx.

In summary, the BL at Point Alpha exhibited the typical well-mixed BL topped by a thin and non-drizzling Sc layer on days without the dominant influence of the synoptic system and the coastal processes, which could be an ideal environment to study the aerosol-cloud interaction. The variability we observed allowed us to document the complex processes in the near-coastal region on some flight days. This dataset will be used for the further study of aerosol-cloud interactions and the evaluation of models operating at a variety of scales to study near-coastal marine stratocumulus during VOCALS-REx. 
Acknowledgements. The observations used in this study were made possible through the dedicated efforts of several individuals. Pilots Mike Hubble and Chris McGuire were instrumental in the development and execution of the flight plans and endured the long ferry of the Twin Otter aircraft to Iquique Chile and back. This work was supported by ONR grant N000140810465 and the NOAA/CPPA Program under grant NA08OAR4320889. Djamal Khelif was supported by ONR grant N000140810438. P. Minnis, K. Ayers, and S. Sun-Mack were supported by the NASA Modeling, Analysis, and Prediction Program, the NASA Clouds and the Earth's Radiant Energy System Project, and the Department of Energy ARM Program through DE-AI02-07ER64546. Graham Feingold was supported by NOAA's Climate Goal.

Edited by: C. R. Mechoso

\section{References}

Albrecht, B. A., Randall, D. A., and Nicholls, S.: Observations of Marine Stratocumulus Clouds During FIRE, B. Am. Meteorol. Soc., 69, 618-626, 1988.

Albrecht, B. A., Bretherton, C. S., Johnson, D., Scubert, W. H., and Frisch, A. S.: The Atlantic Stratocumulus Transition Experiment - ASTEX, B. Am. Meteorol. Soc., 76, 889-904, 1995a.

Albrecht, B. A., Jensen, M. P., and Syrett, W. J.: Marine boundary layer structure and fractional cloudiness, J. Geophys. Res., 100, 14209-14222, doi:10.1029/95JD00827, 1995b.

Allen, G., Coe, H., Clarke, A., Bretherton, C., Wood, R., Abel, S. J., Barrett, P., Brown, P., George, R., Freitag, S., McNaughton, C., Howell, S., Shank, L., Kapustin, V., Brekhovskikh, V., Kleinman, L., Lee, Y.-N., Springston, S., Toniazzo, T., Krejci, R., Fochesatto, J., Shaw, G., Krecl, P., Brooks, B., McMeeking, G., Bower, K. N., Williams, P. I., Crosier, J., Crawford, I., Connolly, P., Allan, J. D., Covert, D., Bandy, A. R., Russell, L. M., Trembath, J., Bart, M., McQuaid, J. B., Wang, J., and Chand, D.: South East Pacific atmospheric composition and variability sampled along $20^{\circ} \mathrm{S}$ during VOCALS-REx, Atmos. Chem. Phys., 11, 5237-5262, doi:10.5194/acp-11-5237-2011, 2011.

Bretherton, C. S., Uttal, T., Fairall, C. W., Yuter, S. E., Weller, R. A., Baumgardner, D., Comstock, K., Wood, R., and Raga, G. B.: The Epic 2001 Stratocumulus Study, B. Am. Meteorol. Soc., 85, 967-977, 2004.

Bretherton, C. S., Wood, R., George, R. C., Leon, D., Allen, G., and Zheng, X.: Southeast Pacific stratocumulus clouds, precipitation and boundary layer structure sampled along $20^{\circ} \mathrm{S}$ during VOCALS-REx, Atmos. Chem. Phys., 10, 10639-10654, doi:10.5194/acp-10-10639-2010, 2010.

Cronin, M. F., Bond, N., Fairall, C., Hare, J., McPhaden, M. J., and Weller, R. A.: Enhanced oceanic and atmospheric monitoring underway in eastern Pacific. Eos, Trans. Amer. Geophys. Union, 83, 210-211, 2002.

Dong, X., Minnis, P., Mace, G. G., Smith Jr., W. L., Poellot, M., Marchand, R. T., and Rapp, A. D.: Comparison of stratus cloud properties deduced from surface, GOES, and aircraft data during the March 2000 ARM Cloud IOP, J. Atmos. Sci., 59, 3256-3284, 2002.

Draxler, R. R. and Rolph, G. D.: HYSPLIT (HYbrid Single-Particle Lagrangian Integrated Trajectory) Model access via NOAA ARL READY Website (http://ready.arl.noaa.gov/HYSPLIT. php), NOAA Air Resources Laboratory, Silver Spring, MD, 2011.

Feingold, G., Remer, L. A., Ramaprasad, J., and Kaufman, Y.: Analysis of smoke impact on clouds in Brazilian biomass burning regions: An extension of Twomey's approach, J. Geophys. Res., 106, 22907-22922, doi:10.1029/2001JD000732, 2001.

Garreaud, R. D. and Muñoz, R.: The diurnal cycle in circulation and cloudiness over the subtropical southeast Pacific: A modeling study. J. Climate, 17, 1699-1710, 2004.

Garreaud, R. D. and Muñoz, R. C.: The Low-Level Jet off the West Coast of Subtropical South America: Structure and Variability, Mon. Weather Rev., 133, 2246-2261, 2005.

Garreaud, R. D., Rutllant, J., Quintana, J., Carrasco, J., and Minnis, P.: CIMAR-5: A snapshot of the lower troposphere over the subtropical southeast Pacific, B. Am. Meteorol. Soc., 92, 21932208, 2001.

George, R. C. and Wood, R.: Subseasonal variability of low cloud radiative properties over the southeast Pacific Ocean, Atmos. Chem. Phys., 10, 4047-4063, doi:10.5194/acp-10-4047-2010, 2010.

Gerber, H., Arends, B. G., and Ackerman, A. S.: A new microphysics sensor for aircraft use, Atmos. Res., 31, 235-252, 1994.

Gerber, H., Frick, G., Malinowski, S. P., Brenguier J.-L., and Burnet, F.: Holes and entrainment in stratocumulus, J. Atmos. Sci., 62, 443-459, 2005.

Ghate, V. P., Albrecht, B. A., Fairall, C. W., and Weller, R. A.: Climatology of surface meteorology, surface fluxes, cloud fraction and radiative forcing over south-east Pacific from buoy observations, J. Climate, 22, 5227-5540, 2009.

Jiang, Q., Wang, S., and O'Neill, L.: Some Insights into the Characteristics and Dynamics of the Chilean Low-Level Coastal Jet, Mon. Weather Rev., 138, 3185-3206, 2010.

Kistler, R., Kalnay, E., Collins, W., Saha, S., White, G., Woollen, J., Chelliah, M., Ebisuzaki, W., Kanamitsu, M., Kousky, V., van den Dool, H., Jenne, R., and Fiorino, M.: The NCEP-NCAR 50-Year Reanalysis: Monthly Means CD-ROM and Documentation, B. Am. Meteorol. Soc., 82, 247-267, 2001.

Klein, S. A. and Hartmann, D. L.: The Seasonal Cycle of Low Stratiform Clouds, J. Climate, 6, 1587-1606, 1993.

Kollias, P., Fairall, C. W., Zuidema, P., Tomlinson, J., and Wick, G. A.: Observations of marine stratocumulus in SE Pacific during the PACS 2003 cruise, Geophys. Res. Lett., 31, L22110, doi:10.1029/2004GL020751, 2004.

Minnis, P., Sun-Mack, S., Chen, Y., Khaiyer, M. M., Yi, Y., Ayers, J. K., Brown, R. R., Dong, X., Gibson, S. C., Heck, P. W., Lin, B., Nordeen, M. L., Nguyen, L., Palikonda, R., Smith Jr., W. L., Spangenberg, D. A., Trepte, Q. Z., and Xi, B.: CERES Edition-2 cloud property retrievals using TRMM VIRS and Terra and Aqua MODIS data, Part II: Examples of average results and comparisons with other data. IEEE Trans. Geosci. Remote Sens., 49, 11, doi:10.1109/TGRS.2011.2144602, 2011a.

Minnis, P., Sun-Mack, S., Young, D. F., Heck, P. W., Garber, D. P., Chen, Y., Spangenberg, D. A., Arduini, R. F., Trepte, Q. Z., Smith Jr., W. L., Ayers, J. K., Gibson, S. C., Miller, W. F., Chakrapani, V., Takano, Y., Liou, K.-N., Xie, Y., and Yang, P.: CERES Edition-2 cloud property retrievals using TRMM VIRS and Terra and Aqua MODIS data, Part I: Algorithms. IEEE Trans. Geosci. Remote Sens., 49, 11, doi:10.1109/TGRS.2011.2144601, 2011b. 
O’Dell, C. W., Wentz, F. J., and Bennartz, R.: Cloud Liquid Water Path from Satellite-Based Passive Microwave Observations: A New Climatology over the Global Oceans, J. Climate, 21, 17211739, 2008.

Painemal, D. and Zuidema, P.: Microphysical variability in southeast Pacific Stratocumulus clouds: synoptic conditions and radiative response, Atmos. Chem. Phys., 10, 6255-6269, doi:10.5194/acp-10-6255-2010, 2010.

Pruppacher, H. R. and Klett, J. D.: Microphysics of Clouds and Precipitation, 954 pp., Kluwer Acad., Dordrecht, Netherlands, 1997.

Rahn, D. A. and Garreaud, R.: Marine boundary layer over the subtropical southeast Pacific during VOCALS-REx - Part 1: Mean structure and diurnal cycle, Atmos. Chem. Phys., 10, 4491-4506, doi:10.5194/acp-10-4491-2010, 2010a.

Rahn, D. A. and Garreaud, R.: Marine boundary layer over the subtropical southeast Pacific during VOCALS-REx - Part 2: Synoptic variability, Atmos. Chem. Phys., 10, 4507-4519, doi:10.5194/acp-10-4507-2010, 2010 b.

Rozendaal, M. and Rossow, W.: Characterizing Some of the Inuences of the General Circulation on Subtropical Marine Boundary Layer Clouds, J. Atmos. Sci., 60, 711-728, 2003.

Sandu, I., Brenguier, J.-L., Geoffroy, O., Thouron, O., and Masson, V.: Aerosol Impacts on the Diurnal Cycle of Marine Stratocumulus, J. Atmos. Sci., 65, 2705-2718, 2008.

Serpetzoglou, E., Albrecht, B. A., Kollias, P., and Fairall, C. W.: Boundary Layer, Cloud, and Drizzle Variability in the Southeast Pacific Stratocumulus Regime, J. Climate, 21, 6191-6214, 2008.

Sharon, T. M., Albrecht, B. A., Jonsson, H. H., Minnis, P., Khaiyer, M. M., Van Reken, T. M., Seinfeld, J., and Flagan, R.: Aerosol and cloud microphysical characteristics of rifts and gradients in maritime stratocumulus clouds, J. Atmos. Sci., 63, 983-997, 2006.

Stevens, B. and Feingold, G.: Untangling aerosol effects on clouds and precipitation in a buffered system, Nature, 461, 607-613, doi:10.1038/nature08281, 2009.

Stevens, B., Lenschow, D. H., Vali, G., Gerber, H., Bandy, A., Blomquist, B., Brenguier, J.-L., Bretherton, C. S., Burnet, F., Campos, T., Chai, S., Faloona, I., Friesen, D., Haimov, S., Laursen, Lilly, D. K., Loehrer, S., Malinowski, S. P., Morley, B., and Petters, M. D.: Dynamics and chemistry of marine stratocumulus-DYCOMS-II, B. Am. Meteorol. Soc., 84, 579593, 2003.

Stevens, B., Moeng, C.-H., Ackerman, A. S., Bretherton, C. S., Chlond, A., De Roode, S., Edwards, J., Golaz, J.-C., Jiang, H., Khairoutdinov, M., Kirkpatrick, M. P., Lewellen, D. C., Lock, A., Müller, F., Stevens, D. E., Whelan, E., and Zhu, P.: Evaluation of large-eddy simulations via observations of nocturnal marine stratocumulus, Mon. Weather Rev., 133, 1443-1462, 2005.
Toniazzo, T., Abel, S. J., Wood, R., Mechoso, C. R., Allen, G., and Shaffrey, L. C.: Large-scale and synoptic meteorology in the south-east Pacific during the observations campaign VOCALSREx in austral Spring 2008, Atmos. Chem. Phys., 11, 49775009, doi:10.5194/acp-11-4977-2011, 2011.

Wang, S., O’Neill, L. W., Jiang, Q., de Szoeke, S. P., Hong, X., Jin, H., Thompson, W. T., and Zheng, X.: A regional real-time forecast of marine boundary layers during VOCALS-REx, Atmos. Chem. Phys., 11, 421-437, doi:10.5194/acp-11-421-2011, 2011.

Wood, R. and Bretherton, C. S.: Boundary Layer Depth, Entrainment, and Decoupling in the Cloud-Capped Subtropical and Tropical Marine Boundary Layer, J. Climate, 17, 3576-3588, 2004.

Wood, R., Mechoso, C. R., Bretherton, C. S., Weller, R. A., Huebert, B., Straneo, F., Albrecht, B. A., Coe, H., Allen, G., Vaughan, G., Daum, P., Fairall, C., Chand, D., Gallardo Klenner, L., Garreaud, R., Grados, C., Covert, D. S., Bates, T. S., Krejci, R., Russell, L. M., de Szoeke, S., Brewer, A., Yuter, S. E., Springston, S. R., Chaigneau, A., Toniazzo, T., Minnis, P., Palikonda, R., Abel, S. J., Brown, W. O. J., Williams, S., Fochesatto, J., Brioude, J., and Bower, K. N.: The VAMOS Ocean-Cloud-Atmosphere-Land Study Regional Experiment (VOCALS-REx): goals, platforms, and field operations, Atmos. Chem. Phys., 11, 627-654, doi:10.5194/acp-11-6272011, 2011.

Wyant, M. C., Wood, R., Bretherton, C. S., Mechoso, C. R., Bacmeister, J., Balmaseda, M. A., Barrett, B., Codron, F., Earnshaw, P., Fast, J., Hannay, C., Kaiser, J. W., Kitagawa, H., Klein, S. A., Köhler, M., Manganello, J., Pan, H.-L., Sun, F., Wang, S., and Wang, Y.: The PreVOCA experiment: modeling the lower troposphere in the Southeast Pacific, Atmos. Chem. Phys., 10, 4757-4774, doi:10.5194/acp-10-4757-2010, 2010.

Zheng, X., Albrecht, B. A., Minnis, P., Ayers, K., and Jonson, H. H.: Observed aerosol and liquid water path relationships in marine stratocumulus, Geophys. Res. Lett., 37, L17803, doi:10.1029/2010GL044095, 2010.

Zuidema, P., Painemal, D., de Szoeke, S., and Fairall, C.: Stratocumulus cloud-top height estimates and their climatic implications, J. Climate, 22, 4652-4666, doi:10.1175/2009jcli2708.1, 2009. 